Universidade de São Paulo

Faculdade de Medicina de Ribeirão Preto

\title{
2016
}

Avaliação da função dos músculos do assoalho pélvico antes e após cirurgia para Prolapso de Órgãos Pélvicos (POP)

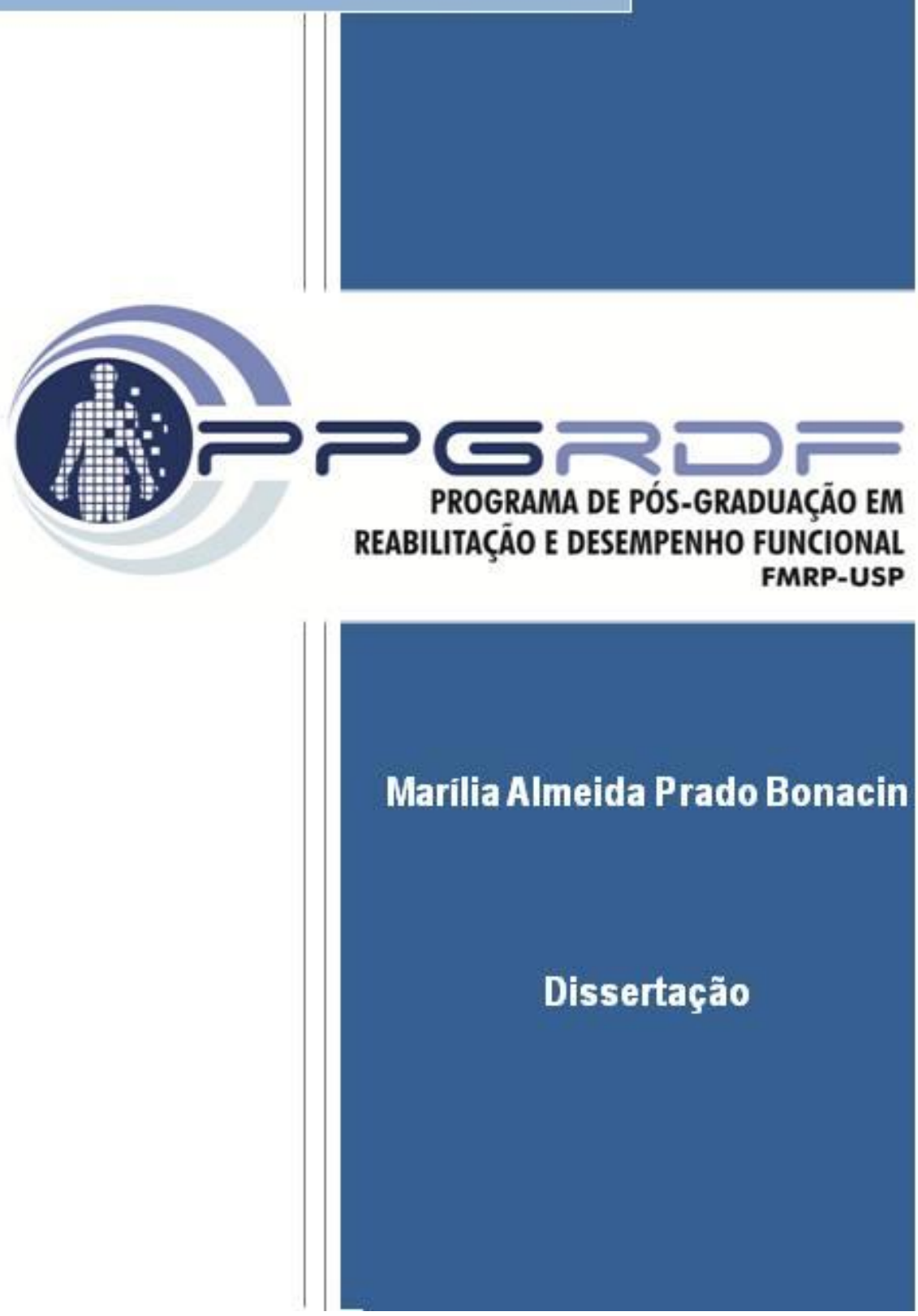




\section{Avaliação da função dos músculos do assoalho pélvico antes e após cirurgia para Prolapso de Órgãos Pélvicos (POP)}

Dissertação

apresentada

ao

Departamento de Biomecânica, Medicina

e Reabilitação do Aparelho Locomotor da Faculdade de Medicina de Ribeirão Preto da Universidade de São Paulo para obtenção do título de mestre em Ciências.

Área de concentração: Reabilitação e Desempenho Funcional

Orientadora: Prof. Dra. Cristine Homsi Jorge Ferreira

Ribeirão Preto 
Autorizo a reprodução e divulgação total ou parcial deste trabalho, por qualquer meio convencional ou eletrônico, para fins de estudo e pesquisa, desde que citada a fonte.

Bonacin, Marília Almeida Prado

Avaliação da função dos músculos do assoalho pélvico antes e após cirurgia para Prolapso de Órgãos Pélvicos (POP). Ribeirão Preto, 2016.

72 p. : il. ; $30 \mathrm{~cm}$

Dissertação de Mestrado, apresentada ao Programa de Pós Graduação em Reabilitação e Desempenho Funcional da Faculdade de Medicina de Ribeirão Preto/USP. Área de concentração: Fisioterapia

Orientadora: Ferreira, Cristine Homsi Jorge.

1. Prolapso de órgão pélvico. 2. Assoalho pélvico. 3. Força muscular. 
Nome : Bonacin, Marília Almeida Prado

Título: avaliação da função dos músculos do assoalho pélvico antes e após cirurgia para Prolapso de Órgãos Pélvicos (POP)

Dissertação

apresentada

ao

Departamento de Biomecânica, Medicina e Reabilitação do Aparelho Locomotor da Faculdade de Medicina de Ribeirão Preto da Universidade de São Paulo para obtenção do título de mestre em Ciências.

Aprovado em:

Banca Examinadora

Prof. Dr.

Instituição:

Julgamento:

Assinatura:

Prof. Dr.

Instituição:

Julgamento:

Assinatura:

Prof. Dr.

Instituição:

Julgamento:

Assinatura: 


\section{DEDICATÓRIA}

Dedico este trabalho à minha família. 


\section{AGRADECIMENTOS}

Agradeço a Deus por me guiar em todas as minhas escolhas, por me proporcionar força que preciso, por me amparar nos momentos difíceis.

Agradeço à minha orientadora Prof. Dra. Cristine, exemplo de profissional comprometida e humana, pela confiança, e por me mostrar o caminho da evidência científica. E também por toda ajuda e carinho.

Agradeço à minha família, por todo amor, atenção, paciência e encorajamento. Em especial, a minha avó Cecy, pelo apoio, carinho e generosidade. Aos meus pais Alice e Hélio pela estrutura e educação. Às minhas irmãs Ticiana e Nathália pelo apoio e compreensão. À minha tia Antonieta por me escutar nos momentos de desespero.

Agradeço ao David Menotti pelo grande incentivo ao meu crescimento profissional.

Agradeço às minhas colegas do laboratório LAFAP por toda ajuda, em especial, Thaiana, companheira de projeto, pelo auxílio e colaboração em todo momento. Agradeço à Flávia por toda ajuda.

Agradeço ao Dr. Luiz Gustavo de Oliveira Brito pela colaboração com a pesquisa.

Agradeço aos funcionários do Hospital das Clínicas da Faculdade de Medicina de Ribeirão Preto e da Unidade de Pesquisa Clínica (UPC) que colaboraram com o andamento da pesquisa.

Agradeço ao Samuel, funcionário do Programa de Pós-Graduação em Reabilitação e Desempenho Funcional.

Agradeço a todos os meus amigos por compreenderem a minha ausência. 
"Há um tempo em que é preciso abandonar as roupas usadas, que já tem a forma do nosso corpo, e esquecer os nossos caminhos, que nos levam sempre aos mesmos lugares. É o tempo da travessia: e, se não ousarmos fazê-la, teremos ficado, para sempre, à margem de nós mesmos."

(Fernando Pessoa) 


\section{RESUMO}

BONACIN, M. A. P. Avaliação da função dos músculos do assoalho pélvico antes e após cirurgia de prolapso de órgão pélvico (POP). 2016. 72 p. Dissertação (Mestrado) - Faculdade de Medicina de Ribeirão Preto, Universidade de São Paulo, Ribeirão Preto, 2016.

Os Prolapsos de Órgãos Pélvicos (POP) apresentam alta prevalência na população feminina causando grande impacto negativo, social, econômico e financeiro. Apesar de alguns estudos indicarem que mulheres com POP apresentam uma diminuição da função dos músculos do assoalho pélvico (MAP), a literatura é escassa em relação à função dos MAP antes e após cirurgia de POP e sua correlação com a severidade do problema, sintomatologia e impacto da qualidade de vida. $O$ objetivo primário desta pesquisa foi avaliar a função dos MAP antes e após o tratamento cirúrgico para correção dos POP. Os objetivos secundários foram avaliar a severidade do POP antes e após a cirurgia; avaliar a sintomatologia e impacto do POP na qualidade de vida antes e após a cirurgia; verificar a correlação entre a função dos MAP com a severidade do POP antes e após a cirurgia; verificar a correlação entre a função dos MAP com a sintomatologia após a cirurgia; e avaliar a percepção de melhora das pacientes após a cirurgia. Trata-se de um estudo observacional prospectivo que recrutou 86 mulheres atendidas no setor de uroginecologia do Hospital das Clínicas da Faculdade de Medicina de Ribeirão Preto com indicação cirúrgica para correção cirúrgica de POP estagio II, III e IV avaliado por meio do $P O P-Q$, destas, 19 não atenderam os critérios de inclusão. Foram incluídas 67 mulheres, e finalizaram o estudo 65. As avaliações ocorreram 15 dias antes e 40 dias após a cirurgia. Para verificação do objetivo primário foram utilizados a escala de Oxford modificada e o perineômetro Peritron $\AA^{\circledR}$. Para verificação dos objetivos secundários foram utilizados o POP-Q, o Pelvic Floor Distress Inventory (PFDI-20), Pelvic Floor Impact Questionnaire (PFIQ-7) e Patient Global Impression of Improvement (PGI-I). O presente estudo encontrou melhora na função dos MAP após a cirurgia, na média da média do equipamento foi $-2,356 \mathrm{cmH}_{2} \mathrm{O}( \pm 8,6797$; $\mathrm{p}=0,0323$ ). Passaram a contrair corretamente os MAP após a cirurgia $23,08 \%$ da amostra. Foi verificada diferença significativa na média do escore total do PFDI-20 de 36,901 pontos $( \pm 27,05 ; p=<0,0001)$, e do PFIQ-7 de 70,417 pontos $( \pm 72,285 ; p=$ $<0,0001$ ) antes e após a cirurgia. Verificou-se que quanto pior a função dos MAP maior é a sintomatologia do POP e seu impacto na qualidade de vida, e quanto maior a severidade do POP menor média da CVM $(p=0,042)$, após a cirurgia. Declararam-se "muito melhor" após a cirurgia $86,15 \%$ das participantes.

Palavras-chave: Avaliação, Fisioterapia, Prolapso de órgãos pélvicos, Assoalho pélvico, Força muscular. 


\begin{abstract}
Bonacin, M. A. P. Evaluation of pelvic floor muscles function before and after pelvic organ prolapse surgery (POP). 2016. 72 p. Thesis (MA) - Ribeirão Preto Medical School, University of São Paulo, Ribeirão Preto, 2016.

Pelvic Organ Prolapse (POP) has a high prevalence in the female population causing great negative social, economic and financial impact. Although some studies indicate that women with POP have a decreased function of the pelvic floor muscles (PFM), the literature is scarce in relation to PFM before and after POP surgery and its correlation with the severity of the problem, symptoms and impact on quality of life. The primary objective of this study was to evaluate the PFM function before and after POP surgery repair. Secondary objectives were to evaluate the severity of POP before and after surgery; assess the symptoms and impact of POP on quality of life before and after surgery; verify the correlation between the PFM function and severity of POP before and after surgery; verify the correlation between PFM function and symptoms after surgery; and to evaluate the patients global perception of improvement after surgery. This is a prospective observational study that recruited 86 women treated at the Urogynecology Unit of the Clinics Hospital of Ribeirão Preto Medical with medical indication for surgical correction of POP stage II, III and IV assessed using the POP-Q, of these, 19 did not meet the inclusion criteria. It was included 67 women, and 65 completed the study. Assessments occurred 15 days before and 40 days after surgery. For verification of the primary endpoint were used the modified Oxford grading scale and perineometer Peritron ${ }^{\mathrm{TM}}$. To check the secondary endpoints were used the POP-Q, the Pelvic Floor Distress Inventory (PFDI-20), Pelvic Floor Impact Questionnaire (PFIQ-7) and the Patient Global Impression of Improvement (PGI-I). This study found improvement in PFM function after surgery, the mean of the mean of the equipment was $-2.356 \mathrm{cmH}_{2} \mathrm{O}( \pm 8.6797$; $p=0.0323$ ). After surgery $23.08 \%$ of the sample was able to contract correctly the PFM. There was a significant difference in the mean total score of PFDI-20 of 36.901 points $( \pm 27.05 ; p=<0.0001)$, and PFIQ-7 70,417 points $( \pm 72,285 ; p=<0.0001)$ after surgery. It was found that the worse the PFM function higher the symptomology of POP and it's impact on quality of life, and the worse is the severity of the POP lowest are the values of the mean MVC $(p=0,042)$. After surgery $86.15 \%$ of the volunteers reported "much better".
\end{abstract}

Keywords: Assessment, Pelvic organ prolapse, Physiotherapy, Pelvic floor, Muscle Strength. 


\section{LISTA DE FIGURAS}

Figura 1. Anatomia normal dos órgãos pélvicos $(A)$, prolapso

do compartimento anterior (B), prolapso apical (C)........................... 21

Figura 2. Pontos de referência para POP-Q................................................ 24

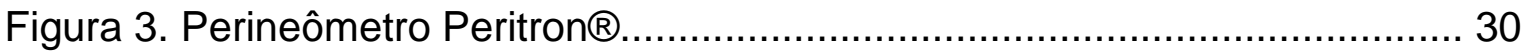

Figura 4. Média da CVM mensurada em $\mathrm{cmH}_{2} \mathrm{O}$ antes e após

a cirurgia utilizando o perineômetro Peritron $\AA$....................................... 37

Figura 5. Média da duração mensurada em segundos antes

e após a cirurgia utilizando o perineômetro Peritron®

Figura 6. Média da média mensurada antes e após a

cirurgia utilizando o perineômetro Peritron $\AA$........................................... 38

Figura 7. Comparação da sintomatologia do POP mensurada

através do PFDI-20 antes e após a cirurgia

Figura 8. Comparação do impacto do POP nas atividades de

vida diária mensurada através do PFIQ-7 antes e após a cirurgia.........40 


\section{LISTA DE TABELAS}

Tabela 1. Comparação da função dos MAP mensurada pela Escala de Oxford Modificada antes e após a cirurgia

Tabela 2. Descrição da sintomatologia do POP mensurada pelo PFDI-20 antes e após a cirurgia

Tabela 3. Descrição do impacto do POP na qualidade de vida mensurado através do PFIQ-7 antes e após a cirurgia

Tabela 4. Comparação da severidade do POP mensurada pelo $P O P-Q$ antes e após a cirurgia.

Tabela 5. Descrição da severidade do POP mensurada pelo POP-Q com a perineometria mensurada pelo Peritron $\AA$ antes da cirurgia

Tabela 6. Descrição da severidade do POP mensurada pelo POP-Q e da perineometria mensurada pelo Peritron ${ }^{\circledR}$ após a cirurgia

Tabela 7. Descrição da severidade do POP mensurada pelo POP-Q antes da cirurgia e da sintomatologia do POP antes e após a cirurgia mensurada pelo PFDI-20.

Tabela 8. Descrição da severidade do POP mensurada pelo POP-Q antes da cirurgia e do impacto do POP na qualidade de vida antes da cirurgia mensurado pelo PFIQ-7.

Tabela 9. Descrição da severidade do POP mensurada utilizando o POP-Q após a cirurgia e de sua sintomatologia utilizando o PFDI-20, antes e após a cirurgia

Tabela 10. Descrição da severidade do POP mensurada utilizando o POP-Q após a cirurgia e do impacto do POP na qualidade de vida mensurado utilizando o PFIQ-7, após a cirurgia

Tabela 11. Descrição da função muscular mensurada utilizando a Escala de Oxford Modificada e da sintomatologia do POP mensurada através do PFDI-20...

Tabela 12. Descrição função muscular mensurada utilizando a Escala de Oxford Modificada e do impacto do POP na qualidade de vida mensurado através do PFIQ-7 


\section{LISTA DE ABREVIATURAS E SIGLAS}

$\begin{array}{ll}\text { CVM } & \text { Contração Voluntária Máxima } \\ \text { CVT } & \text { Comprimento Vaginal Total } \\ \text { ICS } & \text { Internacional Continency Society } \\ \text { CP } & \text { Corpo Perineal } \\ \text { DV } & \text { Desvio Padrão } \\ \text { HG } & \text { Hiato Genital } \\ \text { IMC } & \text { Índice de Massa Corpórea } \\ \text { IU } & \text { Incontinência Urinária } \\ \text { IUE } & \text { Incontinência Urinária de Esforço } \\ \text { IUGA } & \text { International Urogynecological Association } \\ \text { LAFAP } & \text { Laboratório de Avaliação Funcional do Assoalho Pélvico } \\ \text { MAP } & \text { Músculos do Assoalho Pélvico } \\ \text { TMAP } & \text { Treinamento dos Músculos do Assoalho Pélvico } \\ \text { PFDI-20 } & \text { Pelvic Floor Distress Inventory } \\ \text { PFIQ-7 } & \text { Pelvic Floor Impact Questionnaire } \\ \text { PGI-I } & \text { Patient Global Impression of Improvement } \\ \text { POP } & \text { Prolapso de Órgão Pélvico } \\ \text { POP-Q } & \text { Pelvic Organ Prolapse Quantification }\end{array}$




\section{LISTA DE SÍMBOLOS}

$\begin{array}{ll}\mathrm{cm} & \text { Centímetros } \\ \mathrm{cmH} \mathrm{H}_{2} \mathrm{O} & \text { Centímetros de água } \\ \mathrm{g} & \text { Gramas } \\ \mathrm{Kg} & \text { Quilos } \\ \mathrm{m} & \text { Metros }\end{array}$


1. INTRODUÇÃO

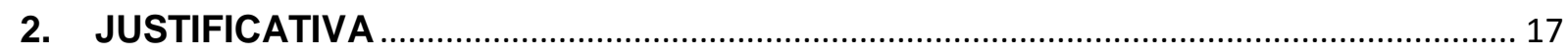

3. HIPÓTESE

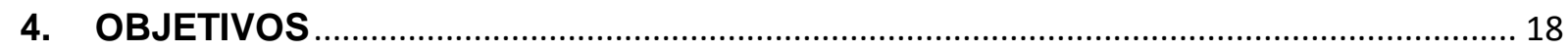

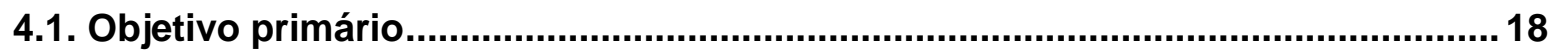

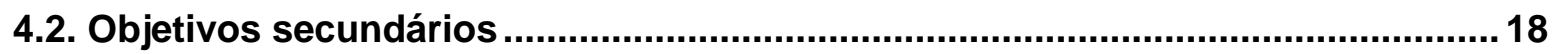

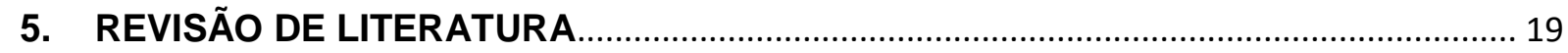

5.1. Anatomia básica do Assoalho pélvico e sua relação com os POP...................... 19

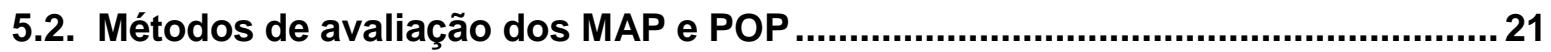

5.3. Tratamento conservador e cirúrgico do POP..................................................... 24

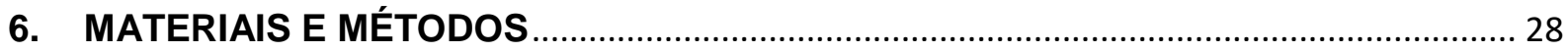

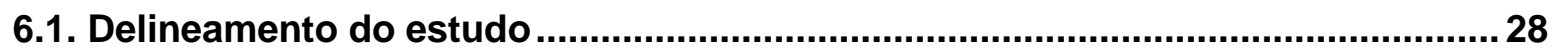

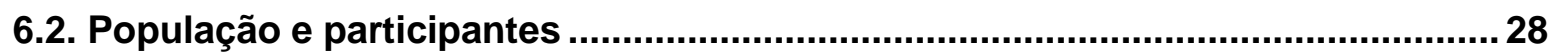

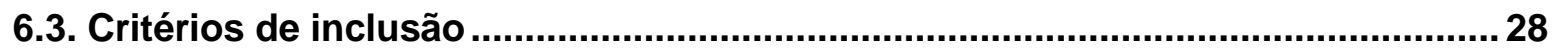

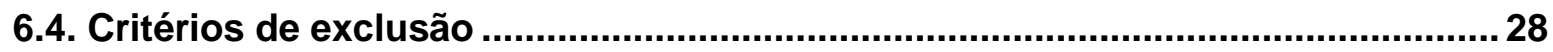

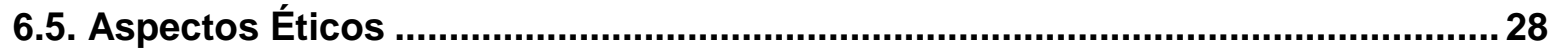

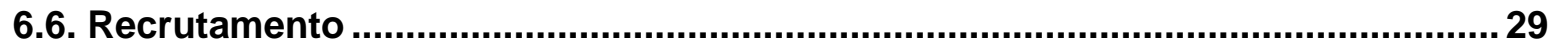

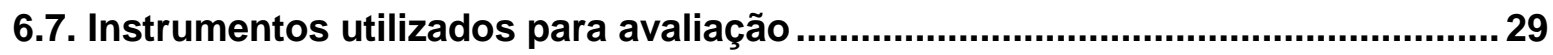

6.8. Procedimentos ...................................................................................................... 31

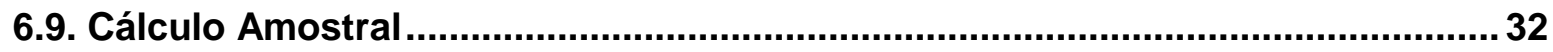

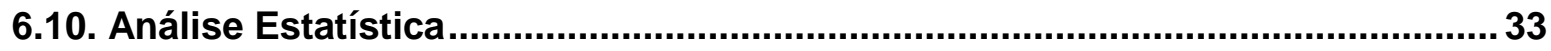

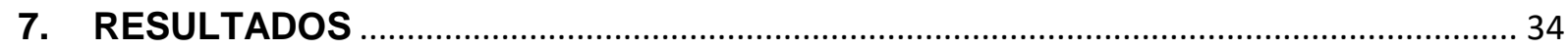

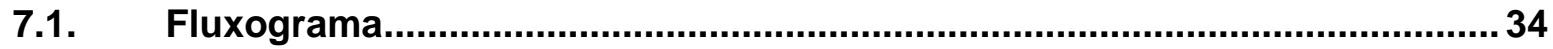

7.2. Caracterização da amostra..............................................................................34

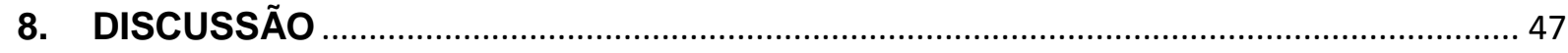

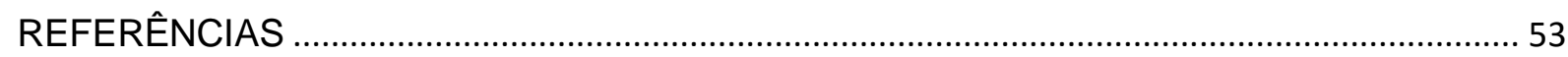

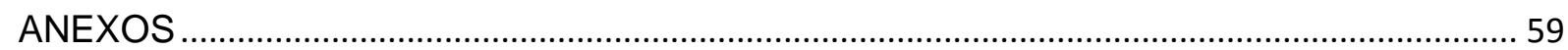




\section{INTRODUÇÃO}

Os Prolapsos de Órgãos Pélvicos (POP) representam um grande problema de saúde pública para a população feminina, causando grande impacto negativo social e econômico (JELOVSEK; BAEBER, 2006). Uma vez instalado o POP pode levar a sintomas como sensação de peso na vagina, dor abdominal, inguinal e lombar (GHETTI et al., 2005).

A prevalência de POP relatada na literatura varia entre 2 a $94 \%$ a depender da população estudada e da definição utilizada (BRAEKKEN et al., 2009). Dentre os fatores de risco para 0 desenvolvimento de POP estão idade avançada, multiparidade, histerectomia, cirurgias prévias para correção de prolapso e desordens de colágeno (MAWAJDEH et al., 2003; BRAEKKEN et al., 2009). Porém outros fatores ainda são controversos, como tipo de parto, obesidade, peso do recém-nascido, tosse crônica e história familiar (KIM et al., 2007; MCLENNAN et al., 2008). A etiologia dos POP é multifatorial e diversos fatores integrados ao longo da vida levam ao seu desenvolvimento (DELANCEY et al., 2008).

Aos 80 anos, $11,1 \%$ das mulheres tem ou tiveram indicação cirúrgica para correção do POP ou incontinência urinária (OLSEN et al., 1997). A cada ano, cerca de 300 a 400 mil mulheres norte-americanas submetem-se a procedimentos cirúrgicos para correção de POP e incontinência urinária, com custo anual de 1 bilhão de dólares (SUBAK et al., 2001; DELANCEY, 2005). Na população brasileira estima-se que aproximadamente 300 mil mulheres por ano são submetidas a cirurgias para correção de POP e incontinência urinária (LUNARDELLI et al., 2009). $\mathrm{Na}$ Austrália foi verificado entre a população feminina um risco de $19 \%$ de cirurgia para correção de POP (SMITH et al., 2010). Diante desses achados, que demonstram uma elevada chance das mulheres australianas sofrerem cirurgia para POP ao longo da vida, os autores concluíram que existe justificativa para prevenção e intervenções que reduzam os custos pessoais e sociais desta condição.

A utilização de métodos conservadores na prevenção e tratamento dos POP pode representar alternativa potencialmente efetiva e segura isoladamente ou associado à terapêutica cirúrgica. Alguns ensaios clínicos randomizados e controlados verificaram a efetividade do treinamento dos músculos do assoalho pélvico (MAP) na melhora objetiva, isto é, anatômica do POP e sua sintomatologia 
(BRAEKKEN et al., 2010; STÜPP et al., 2011) O ensaio clinico randomizado conduzido por Jarvis et al. (2005) avaliou um protocolo fisioterapêutico antes e após cirurgia para correção de POP e incontinência urinária (IU), e verificou um melhora relacionada à IU, qualidade de vida e na função muscular avaliada pela perineometria no grupo que realizou o treinamento, considerando-o efetivo. Entretanto, o ensaio clínico randomizado e controlado realizado por Frawley et al. (2010) que investigou um protocolo fisioterapêutico que incluía um sessão préoperatória e sete no pós-operatório de cirurgia para correção de POP, não verificou melhora dos sintomas relacionados ao POP e na pressão vaginal avaliada pela perineometria no grupo que recebeu o treinamento.

Os MAP são considerados uma parte importante do sistema de suporte dos órgãos pélvicos, o que justifica o efeito do TMAP no tratamento dos POP. Braekken et al. (2010) verificaram que o POP é um condição independentemente associada a função dos MAP e que 30\% menos mulheres com POP tinham os MAP fortes, com boa resistência e com alta pressão de repouso comparadas ao grupo controle. Outros autores também demonstram que mulheres com POP apresentam força reduzida dos MAP (SAMUELSSON et al., 1999; DELANCEY et al., 2007) e que a pressão vaginal de repouso representa um importante marcador do fechamento muscular do hiato levantador (ZACHARIN, 1980; DELANCEY et al., 2007). Entretanto, alguns autores não verificaram força dos MAP reduzida em mulheres com POP (NYGAARD et al., 2008; SLIEKER-TEN HOVE et al., 2010). No estudo de Braekken et al (2009) cerca de 20\% das mulheres com POP apresentaram boa força dos MAP, sugerindo que os POP não relacionam-se somente a fraqueza ou lesão muscular. Esses autores destacam a necessidade de mais pesquisas que avaliem a função dos MAP em mulheres com POP.

O tratamento mais frequente para os POP é cirúrgico, existindo atualmente diversas técnicas disponíveis. Segundo uma revisão sistemática do Cochrane a colpexia abdominal sacral está associada a menores taxas de recidiva e dispareunia que a colpexia vaginal sacroespinhosa, entretanto o primeiro procedimento cirúrgico é mais demorado, caro e o retorno às atividades de vida diária é mais lento (MAHER et al., 2010). A Sociedade Internacional de Continencia Urinária (ICS) e a Associação Internacional de Uroginecologia (IUGA) recomendam que nas cirurgias para POP e IU sejam relatados desfechos objetivos, subjetivos e relacionados à 
qualidade de vida. Os POP e a IU podem ocorrer de maneira isolada ou associados e afetar negativamente a qualidade de vida e função sexual feminina (BARBER et al., 2002; PAULS et al., 2006). Um importante problema relatado após cirurgia para POP e IU é o aparecimento de novos sintomas de IU, urgência, frequência e dificuldade de defecação (PHAM et al., 2009). Diversos autores verificaram que mulheres incontinentes apresentam função deficiente dos MAP avaliados por diferentes métodos (DEVREESE et al., 2007; SHISHIDO et al., 2008; CHAMOCHUMBI et al., 2012), mas isso não foi especificamente estudado em relação ao aparecimento de sintomas após cirurgia para correção de POP.

Diversos estudos tem avaliado o impacto de diferentes técnicas de correção dos POP em inúmeras outras variáveis, entretanto poucos estudos avaliaram a função muscular. Alguns estudos retrospectivos que utilizaram métodos de imagem verificaram que mulheres sem defeitos maiores de levantador do ânus apresentavam melhor suporte pélvico seis semanas após cirurgia para correção de POP (MORGAN et al., 2011) e outros que a lesão por avulsão do levantador do ânus associava-se a POP recorrente em mulheres com cirurgia prévia para correção de POP (MODEL et al., 2010). Apesar disso, parece não existir estudos cujo objetivo primário tenha sido avaliar clinicamente a capacidade de contração correta do MAP e sua função antes e após cirurgia para correção de POP. Da mesma maneira, não se sabe se mulheres com diferentes graus de POP teriam alguma modificação na função muscular após procedimento cirúrgico, especialmente em relação à capacidade de contrair corretamente os MAP e intensidade da contração voluntária máxima. 


\section{JUSTIFICATIVA}

Os MAP constituem uma parte importante do sistema de suporte dos órgãos pélvicos, entretanto apesar das cirurgias para correção de POP serem altamente frequente, poucos estudos avaliaram o impacto da correção cirúrgica dos POP na função dos MAP e sua possível associação com outras variáveis objetivas e subjetivas. Diante disso, este estudo apresenta potencial de contribuir para uma melhor compreensão tanto do papel dos MAP nos desfechos cirúrgicos quanto a respeito do impacto da correção cirúrgica na função dos MAP, o que justifica sua relevância para a Fisioterapia, uma vez que abrirá perspectiva de futuras pesquisas de esclarecer a pertinência em proporcionar rotineiramente as mulheres com indicação cirúrgica para POP uma melhor função dos MAP.

\section{HIPÓTESE}

Ocorre melhora da função dos MAP após a cirurgia. Mulheres com POP menos severo apresentam melhor função muscular dos MAP. 


\section{OBJETIVOS}

\subsection{Objetivo primário}

Avaliar a função dos MAP antes e após o tratamento cirurgico para correção de POP.

\subsection{Objetivos secundários}

Avaliar :

- A severidade anatomica do POP antes e após a cirurgia;

- A sintomatologia e impacto do POP na qualidade de vida antes e após a cirurgia;

- Correlação entre a função dos MAP e a severidade do POP antes e após a cirurgia;

- Correlação entre a função dos MAP e a sintomatologia após a cirurgia;

- A percepção de melhora das pacientes após a cirurgia. 


\section{REVISÃO DE LITERATURA}

\subsection{Anatomia básica do Assoalho pélvico e sua relação com os POP}

Os MAP formam a base do assoalho pélvico e ajudam a manter a continência, servem de apoio para os órgãos pélvicos e fecham as aberturas pélvicas quando contraem (ASHTON-MILLER; DELANCEY, 2007).

Didaticamente, os MAP podem ser divididos em camadas profunda e superficial. A camada profunda, também chamada de diafragma pélvico, é composta pelos músculos pubococcígeo, puboretal e iliococcígeo em conjunto são conhecidos por levantador do ânus, atuam como uma rede elástica de contenção. A camada superficial, também chamada de diafragma urogenital é composta pelos músculos isquiocavernoso, bulboesponjoso e transverso superficial do períneo. Os MAP são envoltos por uma fáscia endopélvica que circunda os órgãos pélvicos e auxiliam no suporte. (WARWICK; WILLIAMS, 1973).

Embora as camadas superficiais e profundas dos MAP sejam estruturas anatômicas diferentes, clinicamente, eles funcionam como uma unidade funcional (BØ; SHERBURN, 2005).

A ação dos MAP não está apenas ligada às funções viscerais, mas também na sustentação dos órgãos e sua posição correta e na manutenção da postura corporal, na deambulação e até mesmo na respiração, capacidade em manter estável a posição do corpo, parado ou em movimento, em equilíbrio com o centro de gravidade caindo sobre a base de apoio. A postura é um fenômeno efetivo, reflexo e involuntário causada pelo tônus, contração e relaxamento dos músculos contra a força da gravidade, e pelo sistema nervoso vestibular (SALA et al., 2014). A função dos MAP é realizada pela contração e relaxamento. Em repouso desempenha o papel de suporte dos órgãos pélvicos. A função de suporte é normal dependendo da posição anatômica, da atividade dos MAP em repouso (apoio ativo) e da integridade da fáscia (apoio passivo). A contração dos MAP resulta em um movimento ventral e cranial do períneo, e um movimento ascendente dos órgãos pélvicos em conjunto com um movimento anterior causado principalmente pelas partes vaginal e retal do levantador do ânus (MESSELINK et al., 2005). 
A atuação dos MAP é essencial para manter uma estabilidade mesmo apresentando tônus variável e contraindo em certas circunstâncias, como micção, defecação e coito. $O$ tônus destes músculos é bastante peculiar, apresentam um estágio intermediário entre tônus e contração, sendo constante, uma série de interações neurológicas sofisticadas que evitam a sua exaustão (ROCCA ROSSETTI, 2016).

A direção das fibras musculares e das fáscias explica seu mecanismo de ação, particularmente bem estudado em mulheres (BARBER, 2005);

As linhas de força desenvolvidas na aponeurose perineal média e no músculo transverso profundo do períneo são dirigidas no sentido dos ramos isquio-púbicos e reforçam a uretra e a ação de fechamento da vagina. Desde modo, a contração muscular proporciona um movimento interno do períneo (CLIPPINGER, 2007).

Prolapso de órgão pévico (POP) refere-se ao deslocamento para baixo da parede vaginal anterior e/ou posterior, e do ápice da vagina ou da cúpula vaginal na vigência de histerectomia (HAYLEN et al., 2010), ocorre a partir de defeitos nos sistemas de suspensão e sustentação (CHOW; RODRIGUEZ, 2013). É um tipo de disfunção do assoalho pélvico que representa um importante problema de saúde pública para as mulheres (SAMUELSSON et al., 1999), além de ser a indicação mais comum de cirurgia ginecológica (BUMP; NORTON, 1998). Estima-se que 50\% das mulheres irão desenvolver POP, entretanto apenas 10 a $20 \%$ dessas buscam avaliação médica (MAHER et al., 2013).

Ocorre perda da normalidade da função, estrutura e sensação quanto à posição dos órgãos pélvicos. Os sintomas pioram quando a mulher permanece longo período na posição em pé, realiza exercício físico ou esforço abdominal, como por exemplo durante a defecação (HAYLEN et al., 2010). As mulheres com POP geralmente têm uma variedade de sintomas do assoalho pélvico dos quais apenas alguns são diretamente relacionados com o prolapso, sendo os sintomas da bexiga, do intestino ou disfunção sexual frequentemente presentes (FABER; FROMER, 2015). O relato é sensação de um nódulo ou "bola" ("algo que vem para baixo"), dor no baixo ventre, sensação de peso, sensação de pressão, ou a necessidade de reduzir digitalmente o prolapso, a fim de defecar ou urinar (ABRAMS et al., 2003). 


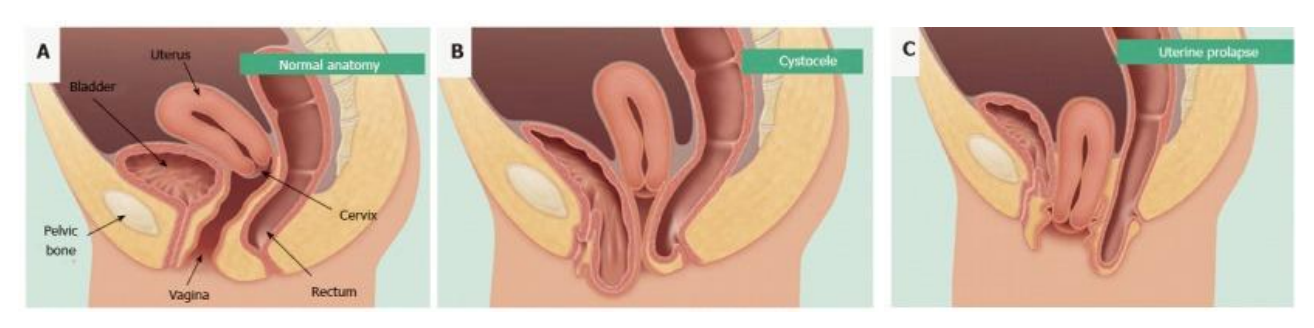

Figura 1. Anatomia normal dos órgãos pélvicos (A), prolapso do compartimento anterior (B), prolapso apical (C).

Fonte: Disponível em: http://www.ncbi.nlm.nih.gov/pmc/articles/PMC4877564/. Acesso em jun. 2016.

A literatura mostra que a prevalência de POP varia de 3 a $94 \%$ dependendo da definição utilizada e população estudada (BRAEKKEN et al., 2009; BARBER e MAHER, 2013). Aos 80 anos, $11,1 \%$ das mulheres têm ou tiveram indicação cirúrgica para a correção de POP ou de incontinência urinária (OLSEN et al., 1997).

Acredita-se que a causa do POP seja multifatorial, e alguns fatores de risco são identificados como não-modificáveis (idade avançada, raça branca, menopausa ou deficiência de estrogênio, doença pulmonar crônica, distúrbio do tecido conectivo e neuropatia) e modificáveis (obesidade, multiparidade, tabagismo, tensão crônica, peso do recém-nascido) (JELOVSEK et al., 2007; CHOW; RODRIGUEZ, 2013)

A relação entre os músculos do assoalho pélvico e o surgimento do $P O P$ foi descrita por DeLancey e ficou conhecida como teoria do barco em doca seca. A descida dos órgãos pélvicos ocorre mediante o relaxamento ou déficit dos MAP, existindo também falha no suporte de tecidos conectivos dos órgãos pélvicos (DELANCEY, 1993).

Sendo os MAP fundamentais para a sustentação dos órgãos pélvicos alguns estudos tem proposto o seu treinamento como forma de prevenção de POP (BØ, 2004).

\subsection{Métodos de avaliação dos MAP e POP}

É de suma importância a avaliação funcional do assoalho pélvico para que se obtenham parâmetros de comparação utilizados em pesquisas científicas e 
estabelecimento de prognósticos na prática clínica. Métodos para avaliar os MAP podem ser classificados como: métodos para medir a capacidade de contração (observação clínica, a palpação vaginal, ultrassom, ressonância magnética, eletromiografia) e medidas para quantificar a intensidade da contração voluntária e outras variáveis da função muscular (teste muscular manual, palpação vaginal, manometria, dinamometria, cones) (BØ; SHERBURN, 2005). Métodos de imagem como ultrassom e a ressonância magnética possibilitam a mensuração da elevação dos MAP (HAHN et al., 1991).

A observação clínica da contração correta dos MAP é verificada como uma ação de aperto, levantamento e fechamento do dedo do examinador, além do movimento para dentro e para cima do períneo (KEGEL, 1948; MESSELINK et al., 2005). A palpação vaginal foi inicialmente descrita e usada por Kegel para ensinar a correta contração dos MAP às mulheres (BØ; FINCKENHAGEN, 2001). A avaliação em tempo real dos MAP pode ser feita também através de imagem de ultrassom e ressonância magnética, sendo que a imagem do primeiro pode ser captada pelo probe supra-púbico ou intra-vaginal (CHRISTENSEN et al., 1995; DIETZ et al., 2001; MORGAN et al., 2009). A Eletromiografia é o estudo da unidade motora, ou seja, é usada para medir a atividade elétrica voluntária ou reflexa dos músculos, no caso dos MAP pode utiliza-se uma sonda vaginal com eletrodo de superfície, observa-se que o número de unidades motoras ativadas aumenta com o aumento da força muscular, quando a força é baixa, enquanto que a frequência de disparo de unidades motoras aumenta a níveis elevados de força (GUNNARSSON; MATTIASSON, 1994; PODNAR; VODUSEK, 2001).

A fim de verificar o estado em que a musculatura se encontra, torna-se necessária a quantificação da função muscular. Existem diversas escalas de palpação vaginal para estimar a função muscular dos MAP, sendo a de Oxford Modificada uma das mais utilizadas por Fisioterapeutas. Sua graduação é a seguinte: 0- sem contração, 1- tênue e trêmula, 2- fraca, 3- moderada, 4- boa (com levantamento), 5- forte, é a mais utilizada por fisioterapeutas (LAYCOCK; JERWOOD, 2001).

O médico austríaco Arnold Kegel (1948) utilizava um dispositivo de pressão vaginal conectado a um manômetro (perineômetro), que mostra a pressão (em 
milímetros de mercúrio) como uma medida da força dos MAP. Ele não relatou quaisquer dados sobre a capacidade de resposta, confiabilidade ou validade de seu método. Atualmente, existem vários tipos de dispositivos para medir a pressão de fechamento vaginal disponíveis, com diferentes tamanhos e parâmetros técnicos (DOUGHERTY et al., 1986; FERREIRA et al., 2011).

Existe o espéculo dinamômetro que mede a força muscular dorsoventral (em newtons) diretamente. Assim como outras ferramentas de medir a força dos MAP, apresentam como desvantagem possuír apenas uma função (aperto e não levantar) e serem afetados pelos aumentos de pressão intra-abdominal ou contrações de outros grupos musculares, tais como os músculos adutores ou glúteos (DUMOULIN et al., 2003; MORIN et al., 2004).

Os cones vaginais foram feitos para serem tanto uma ferramenta de medição como um método de treinamento. Tem por objetivo quantificar a força passiva, pelo maior peso do cone que a mulher consegue segurar dentro da vagina sem contrair voluntariamente os MAP por 1 minuto, e a força ativa, pelo maior peso do cone que a mulher consegue segurar durante 1 minuto com contração voluntária (HERBISON; DEAN, 2013).

Para avaliar e classificar os POP existe o Sistema Baden-Walker, o qual apresenta-se de forma simples e com boa validade inter-examinador. Onde 0normal, 1- protrusão parcial para o hímem, 2- protrusão até o hímem, 3- protrusão parcial para fora do hímem, 4- protrusão completa para fora do hímem (MUIR et al., 2003). Este sistema praticamente não é mais utilizado para fins de pesquisa.

Em 1996, a Sociedade Internacional de Continência (ICS) adotou o Pelvic Organ Prolapse Quantification (POP-Q), um instrumento confiável e reprodutível. O POP é avaliado usando o anel himenal como ponto de referência (zero), e seis pontos definidos são medidos em centímetros acima ou proximal ao hímem (números negativos) e abaixo ou distal ao hímem (números positivos). O examinador deve identificar o comprimento vaginal total (CVT), o hiato genital (HG) que é a medida do meato urtral externo até a linha posterior do hímen, e o corpo perineal (CP) que é a medida da linha posterior do hímen até o orifício anal, os quais não necessitam de esforço da paciente. Então observa pontos de referência: dois na parede anterior, dois na parede superior e dois na parede posterior da vagina. $O$ 
ponto Aa encontra-se localizado a três centímetros para dentro do hímen na linha média da parede anterior da vagina (varia de $-3 \mathrm{a}+3 \mathrm{~cm}$ ), solicita-se o esforço da paciente e observa onde o ponto se deslocou, o ponto $\mathrm{Ba}$ refere-se ao ponto de maior prolapso na parede vaginal anterior, ou seja o mais se exteriorizou, com auxílio de espéculo para afastar a porção posterior da vagina e solicita o esforço da paciente. $\mathrm{O}$ ponto $\mathrm{C}$ é o ponto mais distal do colo uterino ou da cúpula vaginal, utiliza-se o espéculo e esforço da paciente verificando até onde o colo vai em direção ao hímen; Ponto $D$ localiza-se no fórnice vaginal posterior, e solicita o esforço, em caso de histerectomia é omitido. O ponto Ap é análogo ao ponto Aa mas na parede vaginal posterior e a mesma coisa para $\mathrm{Bp}$ ao $\mathrm{Ba}$. De acordo com esta avaliação determina-se o estadiamento do POP: Estádio 0: ausência de prolapso; Estádio I: o ponto de maior prolapso está até $1 \mathrm{~cm}$ para dentro do hímen; Estádio II: ponto de maior prolapso está entre $-1 \mathrm{~cm}$ e $+1 \mathrm{~cm}$ do hímen; Estádio III: o ponto de maior prolapso está a mais de $1 \mathrm{~cm}$ para fora do hímen, mas sem eversão total; Estádio IV: eversão total. (BUMP et al., 1996; PERSU et al., 2011).

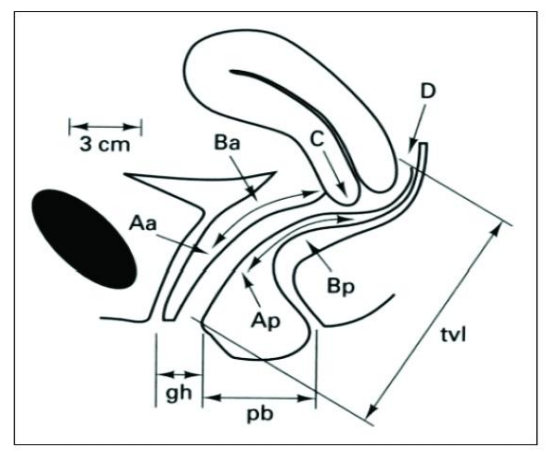

Figura 2. Pontos de referência para POP-Q

Fonte: Disponívem em: https://www.researchgate.net/figure/51063190 fig3 Points-andlandmarks-for-POP-Q-system-examination-Aa-point-A-anterior-Ap-point-A. Acesso em jun. 2016.

\subsection{Tratamento conservador e cirúrgico do $P O P$}

O principal objetivo do tratamento conservador é melhorar a qualidade de vida da mulher, e incluem modificações de estilo de vida (tais como perda de peso e parar de fumar), treinamento dos MAP e o uso de pessário (THIAGAMOORTHY et al., 2014). 
O treinamento dos músculos do assoalho pélvico (TMAP) desempenha um papel importante no tratamento de mulheres com POP.

Com o objetivo de estabelecer a eficácia do TMAP de forma personalizada e individualizada Hagen et al.(2014) desenvolveu um ensaio clínico randomizado e controlado multicêntrico, no Rino Unido, Nova Zelândia e Austrália. Foram incluídas 447 mulheres sintomáticas com POP nos estágios I, II ou III, 225 alocadas no grupo intervenção e 222 no grupo controle. 337 (84\%) completaram o seguimento de 6 meses e 295 (66\%) o de 12 meses. Os achados demonstraram que as mulheres do grupo intervenção relataram menos sintomas do POP em relação ao grupo controle em 12 meses. Portanto, o TMAP personalizado e individualizado é eficaz para a melhora dos sintomas do POP (HAGEN et al., 2014).

O ensaio clínico randomizado de Wiegersma et al. (2014) comparou o efeito do TMAP em mulheres a partir de 55 anos com POP em estágio leve na atenção primária holandesa. $O$ estudo contou com 287 voluntárias que foram randomizadas para o grupo TMAP $(n=145)$ e grupo controle $(n=142), 250(87 \%)$ completaram o estudo. O grupo TMAP melhorou 9,1 pontos no PFDI-20 em relação ao grupo espera. Já nos desfechos secundários (alteração na condição específica e qualidade de vida geral, função sexual, grau de prolapso, função muscular dos MAP e mudança dos sintomas percebida dos pacientes) não houveram diferenças significativas entre os dois grupos. Concluiu-se, então, que apesar do TMAP levar a melhora significativa na pontuação do PFDI-20, a diferença entre os grupos não obteve relevância clínica, mas $57 \%$ das voluntárias do grupo TMAP relataram melhora dos sintomas gerais (WIEGERSMA et al., 2014).

As controvérsias em relação à eficácia do TMAP para tratamento dos POP foram esclarecidas pela revisão sistemática de literatura conduzida por Hagen e Stark (2011), a qual incluiu 6 ensaios clínicos randomizados e controlados e concluiu que esses estudos mostram evidência suficiente para o uso do TMAP como tratamento de mulheres com POP (HAGEN; STARK, 2011).

A intervenção cirúrgica para correção do POP é indicada quando a paciente relata queixa, e os sintomas interferem nas atividades de vida diárias. Seu propósito é aliviar os sintomas, restaurar a anatomia e corrigir alterações funcionais. Sabe-se que nenhuma técnica cirúrgica apresenta total eficácia, o que faz necessário o 
tratamento dos fatores etiológicos e agravantes, a compreensão da importância da participação da paciente no período pós-operatório é fundamental para evitar recidivas (BRUBAKER et al., 2010).

As técnicas cirúrgicas de reconstrução pélvica podem ser efetuadas por via vaginal ou abdominal. Como todas as cirurgias estas não são isentas de riscos ou complicações. Existem complicações intra-operatórias: perfurações vesicais, hemorragias que requerem atitudes cirúrgicas corretivas adicionais, e complicações pós-operatórias: erosão, infecção da tela, infecções urinárias, dispareunia, incontinência urinária. As cirurgias reconstrutivas pélvicas podem apresentar complicações como prejuízo de órgãos vizinhos, hemorragia e infecção (ALVAREZ et al., 2013).

Abaixo estão sintetizadas algumas das principais técnicas cirúrgicas.

- Colporrafia anterior: geralmente envolvem a dissecção da mucosa vaginal em relação à fáscia pubovesicocervical, a fáscia é suturada na linha mediana, dando suporte à bexiga e à uretra. Nos casos de grandes prolapsos, defeito lateral da fáscia ou em recidivas de prolapsos, o uso de telas sintéticas pode ser indicado para uma melhor sustentação (WEBER et al., 2001).

- Reparo paravaginal (lateral): cirurgia indicada para defeitos laterais da fáscia com herniação da bexiga. O objetivo dessa técnica é reconstruir a fáscia pubocervical em sua inserção no arco tendíneo. Faz-se uma sutura da fáscia em toda a extensão de sua inserção no arco tendíneo. Essa correção pode ser feita via abdominal ou vaginal, com ou sem uso de telas sintéticas (DEVAL; HAAB, 2003).

- Colpoperineorrafia: indicada nos defeitos da parede posterior da vagina e corpo perineal, implica na dissecção da mucosa vaginal até o nível superior à retocele, a fáscia retovaginal é suturada na linha mediana. O músculo levantador do ânus pode ou não ser plicado na linha mediana para melhor reforço do septo retovaginal, mas traz como consequência alta taxa de dispareunia (KARRAM; MAHER, 2013).

- Operação de Manchester: A técnica combina colporrafia anterior, amputação plana do colo uterino, fixação dos ligamentos cardinais anteriormente ao útero e colpoperineorrafia para correção de prolapso uterino (DETOLLENAERE et al., 2011). 
- Histerectomia vaginal: considerada a cirurgia de escolha nos casos de prolapso uterino em paciente sem desejo reprodutivo, é empregada nos casos de prolapsos estádios III e IV (PARK; PARAISO, 2008).

- Correção cirúrgica de enterocele: dissecção da colpoperineorrafia estendida até o local da enterocele (fórnice vaginal posterior), a cúpula vaginal é recomposta por meio de sutura dos ligamentos útero-sacro na linha mediana, assim como toda a fáscia retovaginal (DEVAL; HAAB, 2003)

- Fixação no ligamento sacroespinhoso: fixação da cúpula vaginal no ligamento sacroespinhoso (LOVATSIS; DRUTZ, 2002).

- Le Fort: técnica cirúrgica obliterativa empregada no tratamento do grande prolapso uterino e/ou de cúpula vaginal sintomáticos, em pacientes que não mais desejam ter vida sexual, de idade avançada e risco cirúrgico elevado. Uma faixa da mucosa vaginal anterior e outra da posterior são retiradas, e sutura a parede anterior com a parede posterior da vagina, obliterando parcialmente seu lúmen, o que cria um septo largo entre as paredes anterior e posterior da vagina, proporcionando a sustentação uterina e da cúpula vaginal (KRISSI et al., 2015).

- Sacropexia infracoccígea: cirurgia minimamente invasiva em que ocorre colocação de uma faixa livre de tensão, na porção posterior da vagina, para a suspensão da cúpula vaginal, criando um neoligamento útero-sacral artificial, com mínima dissecção (PETROS, 2001).

- Uso de telas: O material sintético é uma opção para a substituição de tecidos deficitários e lesados das mulheres portadoras de prolapsos (CHERMANSKY; WINTERS, 2012).

O estudo coorte retrospectivo de Olsen et al. (1997) encontrou uma taxa de 29,2\% de reoperação para correção de POP nos indivíduos analisados (OLSEN et al., 1997). Na amostra estudada por Clark et al.(2003) $13 \%$ foi submetida à segunda correção cirúrgica de POP no período de aproximadamente 6 anos (CLARK et al., 2003). 


\section{MATERIAIS E MÉTODOS}

\subsection{Delineamento do estudo}

Trata-se de um estudo prospectivo observacional.

\subsection{População e participantes}

Participaram do estudo mulheres atendidas no setor de Uroginecologia do Hospital das Clínicas da Faculdade de Medicina de Ribeirão Preto.

\subsection{Critérios de inclusão}

- Concordância em participar do estudo

- Idade entre 40 e 80 anos;

- Queixa clínica compatível com prolapso genital;

- Indicação médica de cirurgia vaginal para reparo de defeitos anterior, apical e posterior, POP em estágios II, III e IV avaliado por meio do Pelvic Organ Prolapse Quantification (POP-Q);

- Sem cirurgias pélvicas prévias de correção de prolapso de órgãos pélvicos;

- Sem infecção vaginal e urinária presentes;

- Alfabetizadas.

\subsection{Critérios de exclusão}

- Intolerância ou inviabilidade de realizar os exames propostos.

\subsection{Aspectos Éticos}

Este projeto se inseri dentro do projeto intitulado "Avaliação do treinamento dos músculos do assoalho pélvico antes e após cirurgia para correção de prolapso de órgãos pélvicos (POP): ensaio clínico randomizado" que foi aprovado pelo Comitê de Ética em Pesquisa do Hospital das Clínicas de Ribeirão Preto da Faculdade de Medicina de Ribeirão Preto número 5872/2014 (Anexo A). 


\subsection{Recrutamento}

As pacientes foram recrutadas no ambulatório de Uroginecologia da Faculdade de Medicina de Ribeirão Preto da Universidade de São Paulo. A equipe de cirurgiões deste Setor auxiliou na identificação de pacientes elegíveis para o estudo. Uma fisioterapeuta pós-graduanda do Programa de Reabilitação e Desempenho Funcional da FMRP-USP fez o convite para as mulheres que preenchiam os critérios de inclusão participarem do projeto.

\subsection{Instrumentos utilizados para avaliação}

Para avaliação e verificação do desfecho primário foram utilizados os seguintes instrumentos:

- Escala de Oxford Modificada- A avaliação da capacidade de contração dos MAP e classificação da função muscular foi primeiramente avaliada de acordo com a Escala Modificada de Oxford modificada, que consiste em uma escala de 5 pontos, sendo 0-sem contração, 1- tênue e trêmula, 2- fraca, 3- moderada, 4- boa (com levantamento), 5- forte (LAYCOCK; JERWOOD, 2001).

- Perineômetro Peritron ${ }^{\circledR}$ (Cardiodesign, Melbourne, Australia)equipamento que registra as contrações musculares do Assoalho Pélvico e traduz sua intensidade por sinais visuais numa escala de 0 a $300 \mathrm{cmH}_{2} \mathrm{O}$. É constituído por um sensor vaginal inflável $(28 \times 55 \mathrm{~mm})$ recoberto por látex, um monitor com visor de leitura eletrônico e um transdutor de pressão. O equipamento demonstrou boa confiabilidade e validade se utilizado com simultânea observação do movimento interno da sonda durante a contração do MAP (FRAWLEY et al., 2006).

Segundo o manual do equipamento, pico é o valor máximo em $\mathrm{cmH}_{2} \mathrm{O}$, duração é o tempo em segundos a partir de $5 \mathrm{cmH}_{2} \mathrm{O}$, e a média dada pelo equipamento é a relação entre a curva da área pela duração. HANDBOOK Peritron ${ }^{\circledR}$.[201-?]. Para fins de análise neste estudo consideramos as seguintes medidas e terminologia:

1- Média de três mensurações do pico de perineometria, ou seja, o valor mais alto obtido em três mensurações chamamos de média da contração voluntária máxima percebida (média da $\mathrm{CVM}$ ), em $\mathrm{cmH}_{2} \mathrm{O}$;

2- Duração da contração: Média da duração, em segundos; 
3- Relação entre a curva da área pela duração da contração voluntária máxima que é dada pelo equipamento: Média.

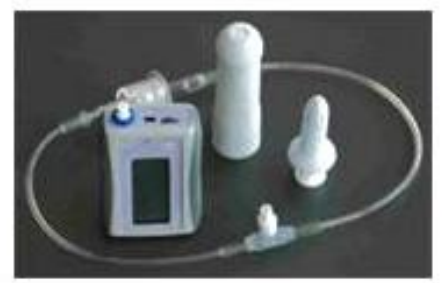

Figura 3. Perineômetro Peritron®

Fonte: Disponével em: http://www.tiendaprimdefisio.com/index.php/productos1/incontinencia/equipoperitron-9300-v-detail Acesso em jun. 2016.

Os desfechos secundários foram avaliados utilizando-se os seguintes instrumentos:

- Pelvic Organ Prolapse Quantification (POP-Q) adotado pela Interntional Continence Society (ICS) em 1996, que classifica e quantifica o prolapso em estágios de 0 a 4, de acordo com a severidade (BUMP et al., 1996; HAYLEN et al., 2016).

- Pelvic Floor Distress Inventory (PFDI-20) Para avaliação do grau do incomodo dos sintomas relacionados ao POP foi utilizado o questionário PFDI-20 que avalia a presença e o incomodo causado por 20 sintomas de desordens do assoalho pélvico, sendo composto de três subquestionários; Sintomas do Prolapso que incluem seis itens, Sintomas Anorretais que incluem oito itens e Sintomas Urinários que incluem seis itens. As pacientes foram questionadas se apresentam os sintomas e quando a resposta é afirmativa, o quanto o sintoma a incomoda em uma escala de 1 que representam nenhum incomodo a 4 que representa incomodo severo. Cada sub-questionário possui um escore de 0 a 100, sendo que o maior escore representa o maior incomodo relacionado aos sintomas (BARBER et al., 2005; Arouca et al., 2016).

- Pelvic Floor Impact Questionnaire (PFIQ-7) foi utilizado para avaliar o impacto dos sintomas nas atividades de vida diária. É composto por três subquestionários que consistem de sete itens cada, o Impacto do Prolapso de Órgão 
Pélvico, o Impacto Anorretais e Impacto Urinário. Cada sub-questionário possui um escore de 0 a 100 , sendo que quanto maior o escore maior o impacto dos sintomas nas atividades de vida diária (BARBER et al., 2005; AROUCA et al., 2016).

- Patient Global Impression of Improvement (PGI-I)- Avaliou a percepção de melhora por meio da questão: De maneira geral você sente que está muito melhor, melhor, quase do mesmo jeito, pior ou muito pior? (YALCIN; BUMP, 2003).

\subsection{Procedimentos}

Duas semanas antes da data da cirurgia foi realizada a primeira avaliação. As mulheres foram convidadas a primeiramente participar de uma entrevista onde responderam questões sobre peso, altura, etnia, nível educacional, data da última menstruação, regularidade menstrual, paridade, tipo de parto, realização de terapia hormonal, tabagismo, trabalho físico pesado no passado ou atual e histórico de treinamento dos MAP. Os questionários acima descritos aplicados por uma pesquisadora auxiliar que não teve contato com os resultados do exame da função dos músculos do assoalho pélvico. Após responderem aos questionários as participantes foram avaliadas quanto a severidade do POP e função dos MAP. O exame foi realizado sempre pela mesma examinadora que não tinha nenhum contato com os resultados dos questionários.

As mulheres foram avaliadas em decúbito dorsal com flexão de joelho, abdução de coxo-femural e pés apoiados na mesa de avaliação. Primeiramente foi avaliada a capacidade de contração dos MAP pela palpação vaginal uni digital realizada com luvas e $5 \mathrm{ml}$ gel lubrificante. E solicitado que a mulher contraia os MAP realizando um movimento para cima e para dentro com a maior força possível. Quando verificada a contração correta a examinadora classificou a mesma segundo a Escala de Oxford Modificada (LAYCOCK; JERWOOD, 2001). A capacidade de contração voluntária dos MAP significa que a paciente é capaz de contraí-los quando solicitado. Considerou-se contração correta dos MAP a contração sentida como uma ação de aperto, levantamento e oclusão do dedo do examinador conforme descrito no documento de estandardização de terminologia relacionada à função e disfunção dos músculos do assoalho pélvico da Sociedade Internacional de Continência (MESSELINK et al., 2005). Esta descrição corresponde ao grau 3 da Escala de Oxford Modificada. 
Em seguida a avaliação dos MAP com o perineômetro foi realizada apenas nas mulheres que apresentarem a capacidade de contrair os MAP, verificada pela palpação vaginal. Utilizando o perineômetro Peritron ${ }^{\circledR}$ (Cardiodesign, Melbourne, Australia) 5 minutos após a avaliação por meio da palpação vaginal. Estando as pacientes na mesma posição o sensor vaginal será introduzido cerca de $3,5 \mathrm{~cm}$ na vagina, em seguida, o aparelho foi calibrado. A voluntária foi orientada a realizar três contrações dos MAP com a maior força possível de modo a evitar a eliminação de urina ou gases. Foram computadas apenas as contrações em que foi observado o movimento interno da sonda vaginal e ausência de movimento de flexão do quadril (FRAWLEY et al., 2006).

Por último avaliou-se a existência ou não de POP utilizando o sistema POP-Q para classificação. A extensão máxima do prolapso foi clinicamente mensurada durante a manobra de valsalva e confirmada pela paciente como sendo a protusão mais severa. $\mathrm{Na}$ avaliação pós-cirúrgica considerou-se recorrência anatômica o estágio do POP-Q $\geq \mathrm{Il}(\geq-1 \mathrm{~cm}$ ) (BUMP et al., 1996). Todas as recomendações da literatura para uma mensuração confiável foram empreendidas (BLAND et al., 1999).

Os materiais permanentes utilizados pertencem ao Laboratório de Avaliação Funcional do Assoalho Pélvico (LAFAP) da Faculdade de Medicina da de Ribeirão Preto da Universidade de São Paulo.

\subsection{Cálculo Amostral}

Utilizando os resultados da perineometria de 14 mulheres que atendiam aos critérios estabelecidos para realização do cálculo amostral, verificou-se uma diferença entre o pré e pós-operatório de $\mu \mathrm{d}=2,17 \mathrm{cmH}_{2} \mathrm{O}$ e $\mathrm{DP}=6,54$. A partir dessas informações foi encontrada uma variância de aproximadamente 43 e utilizado uma comparação por teste t pareado com nível de significância $\alpha$ de 0,05 e o poder do teste $(1-\beta)$ de $80 \%$. O tamanho amostral mínimo encontrado foi de 54 mulheres. Prevendo possíveis perdas de acompanhamento buscou-se incluir pelo menos $25 \%$ a mais de participantes. 


\subsection{Análise Estatística}

Inicialmente, foi utilizada uma análise descritiva dos dados apresentada de forma descritiva, em gráficos e tabelas. Para atender o objetivo do estudo foi utilizado o testes t-Student para dados quantitativos pareados e para analisar as correlações propostas o coeficiente de correlação de Pearson. Este coeficiente quantifica a força de correlação linear entre duas variáveis, e portanto descreve quão bem uma linha reta se ajustaria através de uma nuvem de pontos. Se os pontos caem exatamente sobre uma linha crescente então $r=1$, e se eles caem exatamente sobre uma linha decrescente, $r=-1$.

Para a comparação entre os tempos avaliados, foi utilizado o teste nãoparamétrico de Kruskal-Wallis para as variáveis dependentes. Utilizou-se o software SAS 9. O nível de significância adotado foi $p<0,005$. 


\section{RESULTADOS}

\subsection{Fluxograma}

Foram recrutadas 86 mulheres que tinham cirurgia de correção de POP agendada no Hospital das clínicas da Faculdade de Medicina de Ribeirão Preto entre maio de 2014 e maio de 2016, 19 não atendiam os critérios de inclusão ( 9 não aceitaram participar do estudo, 6 tiveram a cirurgia adiantada e 4 tiveram a cirurgia remarcada), Foram incluídas 67, entretanto 2 tiveram perda de follow up por apresentarem desconforto durante a avaliação após a cirurgia, enfim os dados de 65 voluntárias foram analisados neste estudo.

\subsection{Caracterização da amostra}

Um total de 65 voluntárias foram incluídas neste estudo. A média de idade foi de $62,08( \pm 10,27)$, a média de peso foi de $70,71( \pm 13,83)$, a média de altura foi de $1,57( \pm 0,07)$, a média do IMC foi de $28,76( \pm 5,25)$.

Do total de participantes da amostra estudada $63,08 \%(n=41)$ eram casadas, e $21,54 \%(n=14)$ viúvas, 9,23\% ( $n=6)$ separadas e $6,15 \%(n=4)$ solteiras.

Em relação à profissão $66,15 \%(n=43)$ eram do lar, $15,38 \% \quad(n=10)$ eram prestadoras de serviço doméstico, 10,77\% ( $n=7)$ aposentadas, 6,15\% ( $n=4)$ prestadoras de serviço no comércio ou vendedoras e 1,54\% $(n=1)$ prestadora de serviço administrativo. Quanto à cor da pele $66 \%(n=43)$ da amostra estudada declararam-se brancas, 24,62\% ( $n=16)$ pardas e 9,23\% $(n=6)$ negras.

Quanto ao grau de instrução 69, 23\% ( $n=45)$ possuíam menos de 9 anos de escolaridade $12,31 \%(n=8)$ eram alfabetizadas, 6,15\% $(n=4)$ possuíam 9 anos completos de escolaridade, $6,15 \%(n=4)$ possuíam 12 anos de escolaridade e $6,15 \%$ $(n=4)$ mais de 12 anos de escolaridade. A renda mensal média declarada pelas participantes foi de 2,26 salários mínimos $( \pm 1,49)$.

Foram submetidas previamente a cirurgia pélvica $69,23 \%(n=45)$ da amostra, e $30,77 \%$ ( $n=20)$ não. Declararam-se não tabagistas e não etilistas respectivamente $89,23 \%(n=58)$ e $95,38 \%(n=62)$ da amostra e tabagistas e etilistas respectivamente $10,77 \%(n=7)$ e $4,62 \%(n=3)$.

Em relação à realização de exercício físico $72,31 \% \quad(n=47)$ da amostra declararam ter este hábito no passado e $27,69 \%$ ( $n=18)$ não. Quanto a realização atual de exercício físico apenas $21,54 \%(n=14)$ declararam realizar e $78,46 \%(n=51)$ 
declararam-se sedentárias. Em relação ao estado reprodutivo 13,85\% ( $n=9)$ estavam no menacme e $86,15 \%(n=56)$ na pós-menopausa.

$\mathrm{Na}$ amostra deste estudo, a maioria das participantes $72,31 \% \quad(n=47)$ nunca ouviram falar a respeito do TMAP e 90,77\% ( $n=59)$ nunca haviam realizado o TMAP.

A média de idade do primeiro coito foi de 18,63 anos ( $\mathrm{DP} \pm 4,29)$. Um total de $41,54 \%$ ( $n=27)$ apresenta vida sexual ativa, enquanto $58,46 \%$ ( $n=38)$ não. Entre as mulheres com vida sexual ativa, 29,63\% $(n=8)$ mantinham uma frequência de 2 ou mais vezes por semana; $40,74 \%$ ( $n=11)$ de 1 vez por semana; $18,52 \%(n=5) 1$ vez por mês e $11,11 \%(n=3)$ de 2 vezes por mês. A média de duração do relacionamento afetivo com o parceiro foi 35,36 anos $( \pm 12,92)$.

A média de idade no primeiro parto foi de 20,47 anos $( \pm 3,60)$ e a média no último parto foi de 32,02 anos $( \pm 5,95)$. Em média o peso do maior recém-nascido foi $3.582,21 \mathrm{~g}( \pm 556,71)$.

Quanto ao número de gestações, 1,54\% $(n=1)$ eram nuligestas, 1,54\% $(n=1)$ teve apenas 1 gestação; 13,85\% (n=9) 2 gestações; 23,08\% ( $n=15) 3$ gestações; 16,92\% ( $n=11) 4$ gestações; 43,08\% ( $n=28) 5$ ou mais gestações. Já quanto à paridade $1,54 \%(n=1)$ eram nulíparas; $1,54 \%(n=1)$ tiveram 1 parto; $20 \%(n=13)$ tiveram 2 partos; 23\% ( $n=15)$ tiveram 3 partos; 16,92\% $(n=11)$ tiveram 4 partos; $36,93 \%$ ( $n=24)$ tiveram 5 ou mais partos. Em relação ao número de partos vaginais 4,62\% ( $n=3)$ não tiveram nenhum; 7,69\% $(n=5)$ tiveram $1 ; 87,7 \%(n=57)$ tiveram mais de 1. Já em relação à quantidade de parto cesária, $66,15 \%(n=43)$ não tiveram nenhum; $27,69 \%(n=18)$ tiveram $1 ; 4,62 \%(n=3)$ tiveram 2 e 1,15\% $(n=1)$ tiveram 3. Em relação à quantidade de abortos sofrido, 64,62\% ( $n=42)$ não tiveram nenhum aborto; $24,62 \%(n=16)$ tiveram 1 aborto; 7,69\% $(n=5)$ tiveram $2 ; 1,54 \%(n=1)$ tiveram 4 e $1,54 \%(n=1)$ tiveram 6.

Nesta amostra, $73,02 \% \quad(n=46)$ das participantes sofreram episiotomia, enquanto $26,98 \%$ ( $n=17)$ não.

A função dos MAP foi mensurada por meio da Escala de Oxford Modificada antes e após a cirurgia. Houve aumento de mulheres com melhor função dos MAP após a cirurgia, ou seja, quanto maior a categoria da escala de Oxford modificada melhor a função dos MAP, como verificado na tabela 1. 
Tabela 1. Comparação da função dos MAP mensurada pela Escala de Oxford Modificada antes e após a cirurgia

\begin{tabular}{cccc}
\hline Avaliação & $\begin{array}{c}\text { Escala de Oxford } \\
\text { Modificada }\end{array}$ & $\mathbf{n}$ & $\%$ \\
\hline Antes & 1 & 10 & 15,38 \\
& 2 & 16 & 24,62 \\
& 3 & 32 & 49,23 \\
& 4 & 5 & 7,69 \\
Após & 5 & 2 & 3,08 \\
& 1 & 2 & 3,08 \\
& 2 & 12 & 18,46 \\
& 3 & 24 & 36,92 \\
& 4 & 22 & 33,85 \\
& 5 & 5 & 7,69 \\
\hline
\end{tabular}

$\mathrm{Na}$ avaliação inicial 40\% ( $n=26)$ não contraiam os MAP corretamente, ou seja, apresentaram classificação menor que 3 segundo a Escala de Oxford Modificada, enquanto $60 \%(n=39)$ contraiam corretamente. $\mathrm{Na}$ avaliação realizada 40 dias após a cirurgia de correção do POP, $21,54 \%(n=14)$ não contraíam corretamente os MAP e $78,46 \% \quad(n=51)$ contraíam. Dentre as voluntárias que não contraiam os MAP corretamente antes da cirurgia, 16,92\% ( $n=11)$ continuaram desta forma na avaliação após a cirurgia. Passaram a contrair corretamente os MAP após a cirurgia $23,08 \%(n=15)$ da amostra total estudada. A capacidade de contrair corretamente os MAP foi mantida por $55,38 \%(n=36)$, e apenas $4,62 \%(n=3)$ das participantes que sabiam contrair corretamente os MAP antes da cirurgia passaram a não fazê-lo após a cirurgia. $O$ teste McNemar mostrou uma diferença significativa $p$-valor $=0,0047$.

$\mathrm{Na}$ avaliação pré-cirúrgica a média da contração voluntaria máxima (CVM) foi de $27,10( \pm 17,00)$, a média da duração foi de $5,40( \pm 3,41)$ e média da média foi de $19,75( \pm 13,16)$.

$\mathrm{Na}$ avaliação pós-cirúrgica a média da CVM foi de 29,07 $( \pm 17,87)$, a média da duração foi de $5,72( \pm 2,84)$ e a média da média foi de $22,11( \pm 14,42)$. 
A figura 4 apresenta a comparação 15 dias antes da cirurgia e 40 dias após a cirurgia em relação à média da CVM mensurada utilizando o perineômetro $-1,973$ $( \pm 12,93 ; p=0,2232)$.

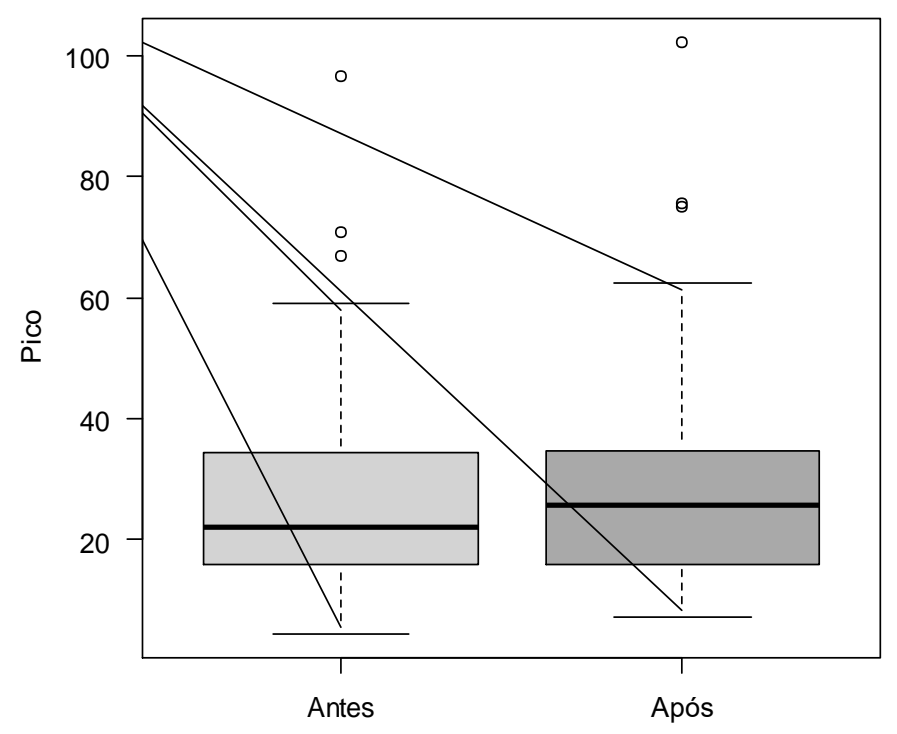

Figura 4: Média da CVM mensurada em $\mathrm{cmH}_{2} \mathrm{O}$ antes e após a cirurgia utilizando o perineômetro Peritron $\AA^{\circledR}$

A figura 5 apresenta a comparação 15 dias antes da cirurgia e 40 dias após a cirurgia em relação à média da duração mensurada utilizando o perineômetro $-0,314$ $( \pm 2,8643 ; p=0,3803)$.

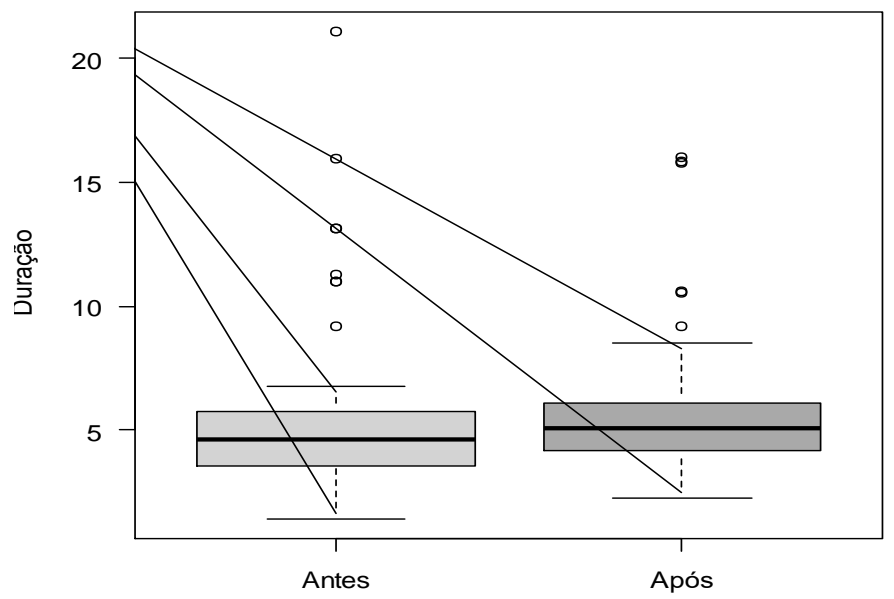

Figura 5: Média da duração mensurada em segundos antes e após a cirurgia utilizando o perineômetro Peritron® 
E a figura 6 apresenta a comparação 15 dias antes da cirurgia e 40 dias após a cirurgia em relação à média da média do equipamento mensurada utilizando o perineômetro $-2,356 \quad( \pm 8,6797 ; \quad \mathrm{p}=0,0323)$, sendo esta mensuração a que demonstrou maior diferença significativa.

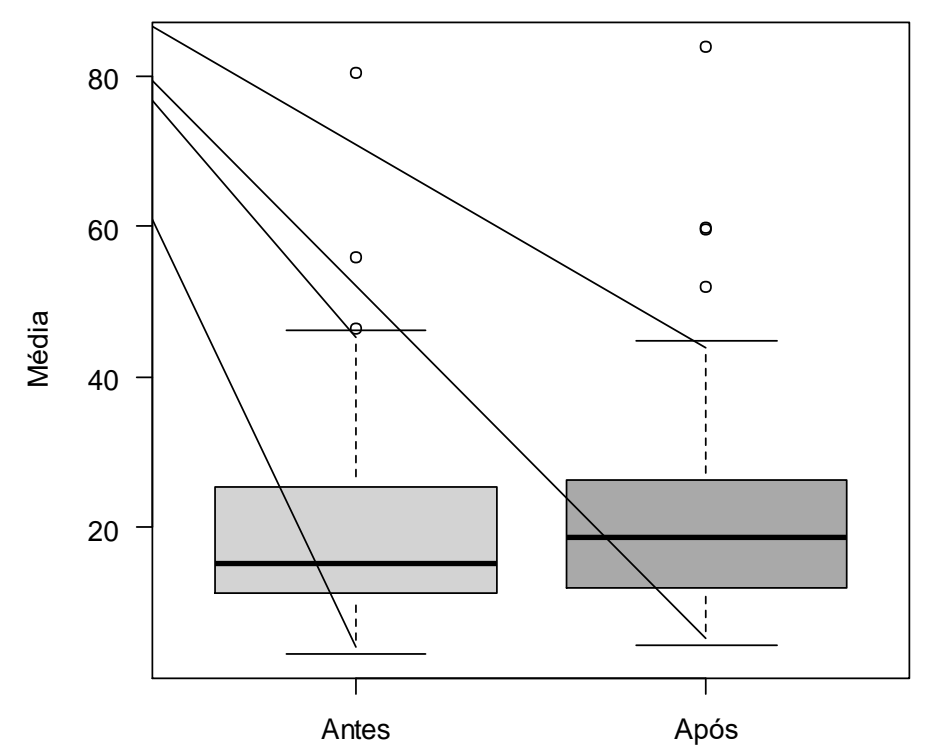

Figura 6: Média da média antes e após a cirurgia utilizando o perineômetro Peritron®

A tabela 2 mostra a média dos escores do PFDI-20 na avaliação 15 dias antes da cirurgia e 40 dias após. Foi observado uma diferença de 36,901 pontos ( \pm 27,$05 ; \mathrm{p}=<0,0001$, teste $t$ pareado) antes e após a cirurgia. A tabela 3 mostra 0 impacto do POP na qualidade de vida através dos escores do PFIQ-7 antes e após a cirurgia. A diferença observada entre o pré e o pós cirúrgico foi de 70,417 pontos $( \pm 72,285 ; p=<0,0001$, teste $t$ pareado). 
Tabela 2. Descrição da sintomatologia do POP mensurada pelo PFDI-20 antes e após a cirurgia.

\begin{tabular}{cccccccc}
\hline Avaliação & Sintomas & $\mathbf{n}$ & Média & Desvio-Padrão & Mínimo & Mediana & Máximo \\
\hline \multirow{2}{*}{ Antes } & Prolapso & 65 & 46,31 & 24,97 & 0,00 & 54,25 & 100,00 \\
& Anorretais & 65 & 29,66 & 21,97 & 0,00 & 25,00 & 78,12 \\
& Urinários & 65 & 47,07 & 28,72 & 0,00 & 50,00 & 100,00 \\
& Escore Total & 65 & 118,23 & 61,36 & 0,00 & 108,75 & 242,50 \\
& & & & & & & \\
Após & Prolapso & 65 & 8,88 & 15,76 & 0,00 & 4,25 & 67,50 \\
& Anorretais & 65 & 14,42 & 15,59 & 0,00 & 9,37 & 62,50 \\
& Urinários & 65 & 17,59 & 22,47 & 0,00 & 7,50 & 92,50 \\
& Escore Total & 65 & 49,48 & 83,57 & 0,00 & 32,50 & 625,00 \\
\hline
\end{tabular}

Tabela 3. Descrição do impacto do POP na qualidade de vida mensurado através do PFIQ-7 antes e após a cirurgia.

\begin{tabular}{cccccccc}
\hline Avaliação & $\begin{array}{c}\text { Impacto na } \\
\text { qualidade vida }\end{array}$ & $\mathbf{n}$ & Média & $\begin{array}{c}\text { Desvio- } \\
\text { Padrão }\end{array}$ & Mínimo & Mediana & Máximo \\
\hline Antes & Urinário & 65 & 40,35 & 35,94 & 0,00 & 36,73 & 100,00 \\
& Anorretal & 65 & 10,75 & 22,05 & 0,00 & 0,00 & 100,00 \\
& Prolapso & 65 & 39,33 & 34,97 & 0,00 & 33,30 & 100,00 \\
& Escore Total & 65 & 88,50 & 73,38 & 0,00 & 73,30 & 300,00 \\
& & & & & & & \\
Após & Urinário & 65 & 9,51 & 22,81 & 0,00 & 0,00 & 100,00 \\
& Anorretal & 65 & 2,47 & 6,70 & 0,00 & 0,00 & 30,00 \\
& Prolapso & 65 & 4,46 & 14,14 & 0,00 & 0,00 & 76,70 \\
& EscoreTotal & 65 & 16,25 & 35,66 & 0,00 & 0,00 & 173,40 \\
\hline
\end{tabular}

Foi encontrada uma diferença na média do escore do questionário PFDI -20 de 68,767 pontos $( \pm 97.659 ; p=<0,0001$, teste $t$ pareado) antes e após a cirurgia, demonstrado na figura 7 . 


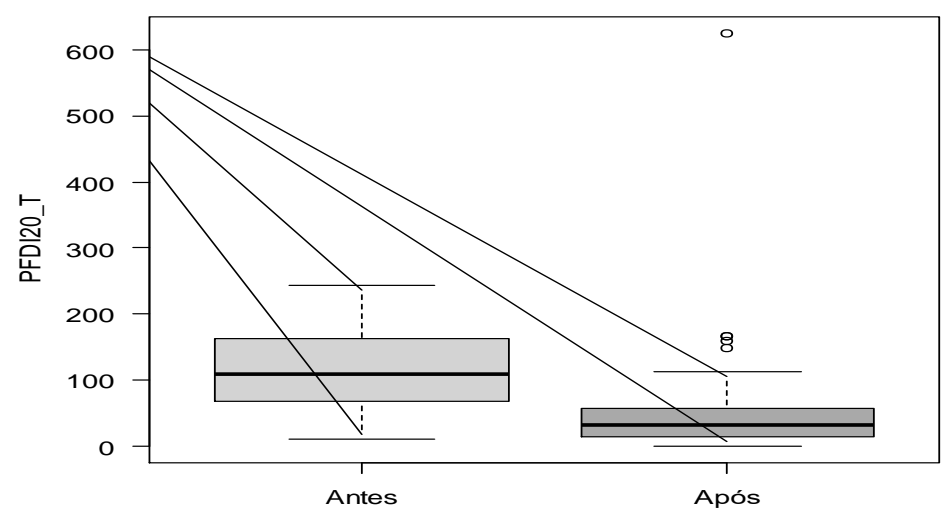

Figura 7: Comparação da sintomatologia do POP mensurada através do PFDI-20 antes e após a cirurgia.

Houve diferença de 70,417 pontos $( \pm 72,285 ; p=<0,0001)$ na análise do escore total do questionário PFIQ-7 antes e após a cirurgia, exibido na figura 8.

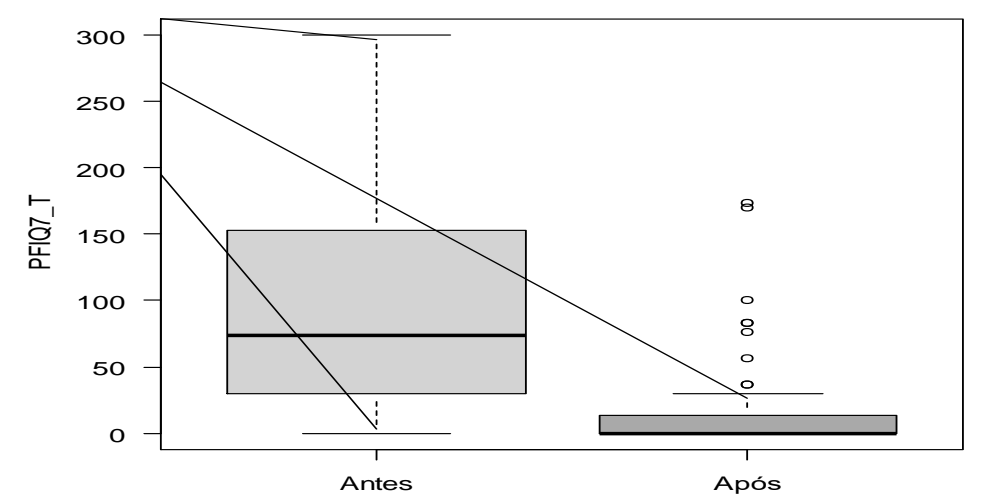

Figura 8: Comparação do impacto do POP nas atividades de vida diária mensurada através do PFIQ7 antes e após a cirurgia.

A severidade do POP foi mensurada antes e após a cirurgia, verificamos que a grande maioria alcançou o objetivo de corrigir o POP, conforme demonstrado na tabela 4. 
Tabela 4. Comparação da severidade do POP mensurada pelo POP-Q antes e após a cirurgia

\begin{tabular}{cccc}
\hline Avaliação & POP-Q & $\mathbf{n}$ & $\%$ \\
\hline Antes & 2 & 27 & 41,54 \\
& 3 & 34 & 52,31 \\
& 4 & 4 & 6,15 \\
\multirow{2}{*}{ Após } & 0 & 22 & 33,85 \\
& 1 & 39 & 60,00 \\
& 2 & 4 & 6,15 \\
\hline
\end{tabular}

Quanto maior a severidade do POP pior a função muscular, como demonstrado na tabela 5 na avaliação antes da cirurgia e na tabela 6 na avaliação após a cirurgia.

Tabela 5. Descrição da severidade do POP mensurada pelo POP-Q com a perineometria mensurada pelo Peritron $\AA$ antes da cirurgia.

\begin{tabular}{cccccccc}
\hline \multicolumn{7}{c}{ Média da CVM Antes da cirurgia } \\
\hline POP-Q & n & Média & Desvio-Padrão & Mínimo & Mediana & Máximo & p-valor \\
2 & 27 & 33,01 & 18,57 & 11,83 & 27,20 & 96,50 & 0,014 \\
3 & 34 & 23,55 & 15,32 & 4,43 & 18,85 & 70,90 & \\
4 & 4 & 17,33 & 3,41 & 13,63 & 16,90 & 21,90 \\
\hline \multicolumn{7}{c}{ Média da Duração Antes da cirurgia } \\
\hline 2 & 27 & 6,73 & 4,37 & 2,87 & 5,37 & 21,07 & 0,007 \\
3 & 34 & 4,28 & 1,92 & 1,43 & 4,08 & 11,27 & \\
4 & 4 & 6,01 & 3,44 & 3,13 & 4,95 & 11,00 & \\
\hline \multicolumn{7}{c}{ Média da média Antes da cirurgia } \\
\hline 3 & 27 & 22,95 & 15,49 & 9,40 & 17,33 & 80,37 & 0,108 \\
4 & 44 & 18,05 & 11,34 & 3,27 & 14,60 & 46,47 & \\
\hline
\end{tabular}


Tabela 6. Descrição da severidade do POP mensurada pelo POP-Q e da perineometria mensurada pelo Peritron $\AA^{\circ}$ após a cirurgia.

\begin{tabular}{cccccccc}
\hline \multicolumn{7}{c}{ Média da CVM após a cirurgia } \\
\hline POP-Q & $\mathbf{N}$ & Média & Desvio-Padrão & Mínimo & Mediana & Máximo & p-valor \\
0 & 22 & 27,34 & 15,81 & 7,13 & 24,03 & 75,00 & 0,042 \\
1 & 39 & 31,53 & 19,23 & 9,27 & 29,33 & 102,17 & \\
2 & 4 & 14,62 & 1,15 & 13,13 & 14,87 & 15,60 & \\
\hline \multicolumn{7}{c}{ Média da Duração após a cirurgia } \\
\hline 1 & 22 & 5,84 & 3,08 & 2,30 & 4,73 & 16,00 & 0,474 \\
2 & 4 & 5,78 & 2,86 & 2,27 & 5,27 & 15,83 & \\
\hline & 4,48 & 1,14 & 3,37 & 4,32 & 5,93 & \\
\hline 0 & 22 & 19,85 & 12,33 & 4,37 & 16,70 & 59,50 & 0,061 \\
1 & 39 & 24,52 & 15,63 & 7,77 & 21,37 & 83,80 & \\
2 & 4 & 11,02 & 1,75 & 9,27 & 10,85 & 13,13 & \\
\hline
\end{tabular}

A tabela 7 mostra o escore total médio dos questionários PFDI 20 antes e depois da cirurgia classificados de acordo com o estádio do POP antes da cirurgia. É possível observar que houve uma diminuição da sintomatologia do POP após a cirurgia em todos os estádios de POP exceto o estádio 4.

Tabela 7. Descrição da severidade do POP mensurada pelo POP-Q antes da cirurgia e da sintomatologia do POP antes e após a cirurgia mensurada pelo PFDI-20.

\begin{tabular}{cccccccc}
\hline \multicolumn{7}{c}{ Avaliação antes da cirurgia } \\
\hline POP-Q & $\begin{array}{c}\text { Sintomatologia } \\
\text { do POP }\end{array}$ & $\mathbf{n}$ & Média & $\begin{array}{l}\text { Desvio- } \\
\text { Padrão }\end{array}$ & Mínimo & Mediana & Máximo \\
\hline 2 & antes & 27 & 125,02 & 68,01 & 10,62 & 125,00 & 242,50 \\
& depois & 26 & 48,07 & 53,67 & 0,00 & 26,25 & 166,25 \\
3 & antes & 34 & 116,03 & 59,18 & 18,13 & 108,13 & 227,50 \\
& depois & 33 & 36,81 & 29,14 & 0,00 & 32,50 & 112,50 \\
4 & antes & 4 & 91,09 & 16,20 & 68,75 & 94,06 & 107,50 \\
& depois & 4 & 171,56 & 302,59 & 3,13 & 29,06 & 625,00 \\
\hline
\end{tabular}


A tabela 8 mostra o escore total médio do questionário PFIQ-7 antes e após a cirurgia classificados de acordo com o estádio do POP na avaliado antes da cirurgia. É possível observar que houve melhora do impacto do POP na qualidade de vida independente do estádio do POP.

Tabela 8. Descrição da severidade do POP mensurada pelo POP-Q antes da cirurgia e do impacto do POP na qualidade de vida antes e após a cirurgia mensurado pelo PFIQ-7.

\begin{tabular}{cccccccc}
\hline \multicolumn{7}{c}{ Avaliação antes da cirurgia } \\
\hline POP-Q & $\begin{array}{c}\text { Impacto na } \\
\text { qualidade de } \\
\text { vida }\end{array}$ & $\mathbf{n}$ & Média & $\begin{array}{l}\text { Desvio- } \\
\text { Padrão }\end{array}$ & Mínimo & Mediana & Máximo \\
\hline 2 & antes & 27 & 86,92 & 80,26 & 0,00 & 46,60 & 300,00 \\
& depois & 27 & 26,41 & 49,12 & 0,00 & 3,30 & 173,40 \\
3 & antes & 34 & 90,56 & 68,59 & 0,00 & 80,00 & 216,70 \\
& depois & 33 & 10,29 & 20,54 & 0,00 & 0,00 & 100,10 \\
4 & antes & 4 & 81,65 & 84,53 & 0,00 & 63,30 & 200,00 \\
& depois & 4 & 000 & 0,00 & 0,00 & 0,00 & 0,00 \\
\hline
\end{tabular}

A tabela 9 mostra o escore total médio dos questionários PFDI 20 antes e após a cirurgia classificados de acordo com a severidade do POP após a cirurgia. É possível observar que houve uma diminuição da sintomatologia do POP após a cirurgia em todos os estádios.

Tabela 9. Descrição da severidade do POP mensurada utilizando o POP-Q após a cirurgia e de sua sintomatologia utilizando o PFDI-20, antes e após a cirurgia.

\begin{tabular}{cccccccc}
\hline \multicolumn{7}{c}{ Avaliação após a cirurgia } \\
\hline POP-Q & $\begin{array}{c}\text { Sintomatologia } \\
\text { do POP }\end{array}$ & $\mathbf{n}$ & Média & $\begin{array}{c}\text { Desvio- } \\
\text { Padrão }\end{array}$ & Mínimo & Mediana & Máximo \\
\hline 0 & antes & 22 & 113,36 & 65,26 & 15,62 & 109,38 & 242,50 \\
& depois & 21 & 64,66 & 134,20 & 0,00 & 26,00 & 625,00 \\
\multirow{2}{*}{1} & antes & 39 & 118,92 & 60,33 & 10,62 & 108,75 & 227,50 \\
& depois & 38 & 43,04 & 43,70 & 0,00 & 32,50 & 166,25 \\
2 & antes & 4 & 138,26 & 60,72 & 73,75 & 133,40 & 212,50 \\
& depois & 4 & 39,37 & 19,42 & 18,75 & 36,56 & 65,62 \\
\hline
\end{tabular}


A tabela 10 mostra o escore total médio do questionário PFIQ-7 antes e após a cirurgia classificados de acordo com o estádio do POP após a cirurgia. É possível observar que houve melhora do impacto do POP na qualidade de vida independente do estádio do POP.

Tabela 10. Descrição da severidade do POP mensurada utilizando o POP-Q após a cirurgia e do impacto do POP na qualidade de vida mensurado utilizando o PFIQ-7, antes e após a cirurgia.

\begin{tabular}{cccccccc}
\hline \multicolumn{7}{c}{ Avaliação após a cirurgia } \\
\hline POP-Q & $\begin{array}{c}\text { Impacto na } \\
\text { qualidade de vida }\end{array}$ & $\mathbf{n}$ & Média & $\begin{array}{l}\text { Desvio- } \\
\text { Padrão }\end{array}$ & Mínimo & Mediana & Máximo \\
\hline 0 & antes & 22 & 83,31 & 68,65 & 0,00 & 68,30 & 216,70 \\
& depois & 22 & 12,27 & 27,29 & 0,00 & 0,00 & 100,10 \\
\multirow{2}{*}{1} & antes & 39 & 94,70 & 78,84 & 0,00 & 76,60 & 300,00 \\
& depois & 38 & 20,16 & 41,58 & 0,00 & 3,30 & 173,40 \\
2 & antes & 4 & 56,63 & 33,00 & 13,30 & 59,95 & 93,30 \\
& depois & 4 & 4,15 & 6,30 & 0,00 & 1,65 & 13,30 \\
\hline
\end{tabular}

A tabela 11 descreve a média do escore total dos questionários PFDI-20 antes e após a cirurgia de POP classificados de acordo com a escala de Oxford modificada. Verificou-se que houve diminuição na sintomatologia e no impacto do POP na qualidade de vida após a cirurgia, exceto na categoria 1 da Escala de Oxford modificada. As mulheres que tiveram melhor função muscular antes da cirurgia apresentaram maior melhora na sintomatologia do POP após a cirurgia. 
Tabela 11. Descrição da função muscular mensurada utilizando a Escala de Oxford Modificada e da sintomatologia do POP mensurada através do PFDI-20.

\begin{tabular}{cccccccc}
\hline $\begin{array}{c}\text { Escala Oxfod } \\
\text { Modificada }\end{array}$ & Sintomatologia & $\mathbf{n}$ & Média & Padrão & Mínimo & Mediana & Máximo \\
\hline 1 & Antes & 10 & 107,14 & 47,53 & 30,00 & 96,25 & 186,87 \\
& Depois & 9 & 111,80 & 198,30 & 3,12 & 36,25 & 625,00 \\
2 & Antes & 16 & 133,42 & 70,42 & 18,13 & 131,25 & 242,50 \\
& Depois & 16 & 50,18 & 48,43 & 0,00 & 34,06 & 166,25 \\
3 & Antes & 32 & 108,77 & 58,26 & 10,62 & 105,63 & 226,80 \\
& Depois & 31 & 33,14 & 33,49 & 0,00 & 32,50 & 158,75 \\
\multirow{2}{*}{4} & Antes & 5 & 152,12 & 70,73 & 47,50 & 167,50 & 227,50 \\
& Depois & 5 & 55,11 & 50,29 & 9,37 & 32,50 & 112,50 \\
5 & Antes & 2 & 118,75 & 86,62 & 57,50 & 118,75 & 180,00 \\
& Depois & 2 & 19,38 & 7,95 & 13,75 & 19,38 & 25,00 \\
\hline
\end{tabular}

Na tabela 12 é possível verificar que as mulheres que tiveram melhor função muscular antes da cirurgia apresentaram menor impacto do POP na qualidade de vida após a cirurgia.

Tabela 12. Descrição da função muscular mensurada utilizando a Escala de Oxford Modificada e do impacto do POP na qualidade de vida mensurado através do PFIQ-7.

\begin{tabular}{cccccccc}
\hline $\begin{array}{c}\text { Escala Oxford } \\
\text { Modificada }\end{array}$ & $\begin{array}{c}\text { Impacto na } \\
\text { qualidade de } \\
\text { vida }\end{array}$ & $\mathbf{n}$ & Média & $\begin{array}{c}\text { Desvio- } \\
\text { Padrão }\end{array}$ & Mínimo & Mediana & Máximo \\
\hline 1 & Antes & 10 & 116,96 & 50,76 & 63,30 & 101,55 & 193,30 \\
& Depois & 9 & 24,44 & 39,11 & 0,00 & 3,33 & 100,10 \\
2 & Antes & 16 & 119,58 & 84,65 & 0,00 & 103,30 & 300,00 \\
& Depois & 16 & 12,07 & 21,38 & 0,00 & 3,30 & 83,30 \\
3 & Antes & 32 & 63,23 & 67,44 & 0,00 & 36,65 & 206,70 \\
& Depois & 32 & 12,70 & 33,49 & 0,00 & 0,00 & 170,00 \\
4 & Antes & 5 & 100,62 & 80,67 & 13,30 & 90,00 & 216,70 \\
& Depois & 5 & 38,68 & 75,81 & 0,00 & 0,00 & 173,40 \\
5 & Antes & 2 & 71,65 & 40,09 & 43,30 & 71,65 & 100,00 \\
& Depois & 2 & 19,95 & 23,55 & 3,30 & 19,95 & 36,60 \\
\hline
\end{tabular}


A correlação entre a pressão vaginal e o impacto do POP na qualidade de vida apresentou diferença significativa entre o domínio Prolapso após a cirurgia com a média da média após a cirurgia $(p=0,0182)$, do escore total após a cirurgia com a média da CVM após a cirurgia $(p=0.0465)$, do escore total após a cirurgia com a média da média após a cirurgia $(p=0,0452)$.

Através dos dados do questionário PGI-I, que avalia o grau de melhora relatado pela paciente, $66,15 \%(n=43)$ das voluntárias declararam-se muito muito melhor, 20\% ( $n=13)$ muito melhor, 6,15\% $(n=4)$ sem mudanças, $4,62 \%(n=3)$ um pouco melhor e $3,08 \%(n=2)$ um pouco pior. 


\section{DISCUSSÃO}

Este estudo objetivou avaliar a função dos MAP antes e após o tratamento cirúrgico para correção de POP. A amostra estudada tinha indicação para correção cirurgica dos POP, apresentava-se sintomática no pré-cirurgico e com POP de moderado a severo.

A literatura considera que 0 POP apresenta gênese multifatorial e se desenvolve gradativamente (JELOVSEK et al., 2007; CHOW; RODRIGUEZ, 2013). Alguns fatores de risco para o desenvolvimento dos POP são: idade avançada, obesidade, multiparidade, traumatismo no AP, histerectomia, desordens de colágeno, parto vaginal, peso do recém-nascido e historia familiar (MAWAJDEH et al., 2003; HALLOCK; HANDA, 2016). A amostra deste estudo teve um alto percentual de multíparas e mulheres que tiveram parto instrumentalizado. $O$ estudo de Scarabotto e Riesco (2006) encontrou uma maior ocorrência de parturientes com laceração perineal quando o peso de seus recém-nascidos eram iguais ou maiores que 3.000 gramas (SCARABOTTO; RIESCO, 2006), o presente estudo encontrou uma média $3582,21 \mathrm{~g}( \pm 556,71)$ para o peso do maior recém-nascido.

Não foi objetivo primário deste estudo avaliar a eficácia da cirurgia e sim utilizar a correção do POP para estudar o seu impacto clínico na função muscular do assoalho pélvico. Apesar disso foi possível observar uma melhora significativa dos sintomas de POP, sintomas urinários e anaorretais após a cirurgia e a correção satisfatóra do POP foi obtida na maior parte da amostra. Não houveram recidivas, entretanto o período avaliado após a cirurgia foi muito curto, de apenas 40 dias. $\mathrm{O}$ presente estudo incluiu mulheres que foram submetidas a diferentes técnica cirurgicas vaginais para reparo de defeitos anterior, apical e posterior. A revisão sistemática de literatura conduzida por Maher et al. (2010) relacionada a eficácia de diferentes abordagens cirurgicas no tratamento de mulheres com POP enfatizou a importancia de incluir-se desfechos que avaliem a percepção de melhora das pacientes. No presente estudo a maioria das pacientes declararam-se pelo menos muito melhor após a correção cirúrgica do POP. 
Apesar dos bons resultados cirúrgicos com o uso de diferentes técnicas utilizadas atualmente, existe consenso a respeito da necessidade de opções conservadoras de tratamento devido ao fato das taxas de recidiva em um período de cinco anos ainda serem consideradas altas (OLSEN et al., 1997; CLARK et al., 2003). Ademais a prevalencia de POP entre mulheres com idade avançada e com risco cirurgico aumentado é alta (MAWAJDEH et al., 2003; CHOW e RODRIGUEZ, 2013). Apesar da revisão de literatura conduzida por Hagen and Stark (2011) indicar que existe evidência que o TMAP é eficaz no tratamento dos sintomas e severidade dos POP, não há evidencia de que adiciona-lo a cirurgia poderia melhorar os resultados cirurgicos.

Os resultados deste estudo sugerem que a correção dos POP poderia respresentar uma menor sobrecarga muscular no assoalho pélvico, possibilitando uma melhor função muscular quarenta dias após a cirurgia. Este achado indica talvez o motivo para um tamanho de efeito pequeno quando se comparam mulheres de grupos controle que só sofreram cirurgia com mulheres que receberam adicionalmente o TMAP. Os resultados dos ensaios clinicos randomizados e controlados que avaliaram a função dos MAP o fizeram apenas 3 meses após a cirurgia (JARVIS et al., 2005; FRAWLEY et al., 2010) e foram contraditórios. O estudo de Frawley et al. (2010) não encontrou diferença nos valores de perineometria 3 meses após a cirurgia entre as mulheres que realizaram e não realizaram o TMAP. Já o estudo de Jarvis et al. (2005) verificaram uma melhor função dos MAP utilizando a mesma marca de perineometro.

Na revisão sistemática conduzida por Bø (2012) com o objetivo de apresentar e discutir evidência científica de ensaios clínicos randomizados que traziam o TMAP no tratamento de incontinência urinária de esforço, prolapso de órgãos pélvicos $\mathrm{e}$ disfunção sexual, ela verificou que o TMAP tem nível 1 e grau A de recomendação para o tratamento de IUE, e 5 ensaios clínicos randomizados mostraram que 0 TMAP é efetivo no controle do estadiamento, dos sintomas e na morfologia do POP. Entretanto há falta de estudos que apresentem seus efeitos na disfunção sexual. Portanto, o TMAP deve ser a primeira linha de tratamento para IUE e POP desde que se ofereça supervisão adequada. Apesar disso, não existe evidência que associar-se o TMAP a cirurgia possa melhorar os resultados cirúrgicos (LAKEMAN 
et al., 2013) e há a necessidade de que sejam conduzidos ensaios clínicos randomizados e controlados para esclarecer esta questão.

$\mathrm{Na}$ realidade apesar de haver um reconhecimento do papel do suporte muscular adequado na sustenção dos orgãos pélvicos, ainda existem muitas dúvidas e incertezas relacionadas ao tema. O estudo Guetti et al. (2005) avaliou medidas clínicas da função dos músculos do assoalho pélvico (MAP) correlacionados com a gravidade do prolapso genital. Este estudo retrospectivo transversal avaliou 1037 mulheres. Maior severidade de POP mensurada através do POP-Q foi correlacionada com da função do músculo levantador do ânus, mensurada pela Escala de Oxford Modificada e tamanho do hiato do levantador do ânus, medido por exame digital. Severidade de prolapso correlacionou-se moderadamente com hiato genital $(r=0,5, p<0,0001)$ e com o hiato do levantador do ânus ( $r$ transversal $=0,4, p<0,0001 ; r$ longitudinal $=0,5, p<0,0001$ ), mas fracamente com a Escala de Oxford Modificada $(r=-0,16, p<0,0001)$. O hiato do levantador do ânus correlaciona-se com o hiato genital ( $r=0,5, p<0,0001)$, mas não com o corpo perineal $(r=0,06, p=0,06)$. Tanto $o$ hiato genital quanto 0 tamanho do hiato do levantador do ânus estão associados com a gravidade do prolapso. O tamanho do hiato do levantador do ânus correlaciona-se mais fortemente à gravidade do prolapso do que com a função dos MAP pela escala Oxford Modificada. Então acredita-se que a musculatura do assoalho pévico integra diminua as chances de surgimento POP, e até mesmo recidivas.

Estudos anteriores apontaram a relação entre POP e função dos MAP (ZACHARIN, 1980; SAMUELSSON et al., 1999; DELANCEY et al., 2007; BRAEKKEN et al., 2010). Braekken et al. (2010) verificaram que o POP é uma condição independentemente associada a função dos MAP e que 30\% a menos das mulheres com POP apresentam os MAP fortes. Outros autores verificaram que mulheres com POP apresentam a força dos MAP reduzida, apesar disso outros autores não encontraram esta relação (NYGAARD et al., 2008; SLIEKER-TEN HOVE et al., 2010).

O presente estudo encontrou aumento nos valores da Escala de Oxford Modificada após a cirurgia de correção de POP, além disso verificou-se que um percentual significativo de mulheres passaram a contrair corretamente os MAP. Entretanto, não é possível garantir que estas mulheres não tenham tido um melhor desempenho em decorrência de já terem realizado o exame e recebido instruções 
no pré-cirurgico. A ausência de um grupo controle constitui-se em uma limitação do presente estudo, entretanto os resultados do estudo prospectivo controlado de Chen et al. (2014) corroboram os achados do presente estudo apesar da avaliação ter sido conduzida 3 meses após a cirurgia. Esses autores tiveram o objetivo de avaliar a função dos MAP em pacientes com POP nos períodos pré e pós-operatórios utilizando a palpação vaginal classificada segunda a escala de Oxford modificada e eletromiografia de superfície. Eles analisaram dois grupos, um incluiu 74 pacientes com POP submetidas à cirurgia reconstrutiva pélvica e outro grupo controle contendo 30 pacientes que não apresentavam POP, portanto não seriam submetidas à cirurgia reconstrutiva. Apenas 68 pacientes do grupo com POP concluíram as avaliações, que aconteceram no dia da admissão para a cirurgia e 3 meses após a cirurgia. Dessas 68 pacientes, 64 (94,1\%) tiveram cura objetiva do POP. Através da palpação vaginal observou-se o aumento significante da força dos MAP das pacientes do grupo POP após a cirurgia, entretanto ainda menor que os valores do grupo controle. $E$ também na eletromiografia a atividade elétrica dos MAP aumentou significativamente no grupo POP após a cirurgia. Os autores concluíram que a função dos MAP melhorou após 3 meses da data da cirurgia reconstrutiva pélvica, baseado na palpação vaginal e na eletromiografia de superfície dos MAP e sugerem a inclusão da avaliação funcional dos MAP na avaliação global de cirurgias reconstrutivas pélvicas.

Oversand et al. (2015) estudaram mulheres com sintomas de incontinência urinária e POP e encontraram forte associação entre a Escala de Oxford Modificada com sinais (medidas objetivas) e sintomas (medidas subjetivas) de POP, tanto no exame clínico quanto em medidas de ultrassonografia translabial (OVERSAND et al., 2015).

Assim como o presente estudo encontrou melhora da função dos MAP após cirurgia de correção de POP, Wang et al. (2013) encontrou uma melhora da função dos MAP em pacientes com POP após o procedimento Prolift 3 meses após a cirurgia, no entanto sua medida de desfecho foi obtida através dos resultados de eletromiografia de superfície. Trata-se de um estudo não-randomizado controlado, contendo um grupo de pacientes com POP submetidas a Prolift composto por 37 pacientes e outro grupo sem POP com 30 pacientes. Foram realizados a quantificação $P O P-Q$ e a eletromiografia de superfície dos MAP no momento da admissão para a cirurgia e no terceiro mês pós-operatório. Este estudo encontrou 
como resultado a cura de 36 das 37 pacientes do grupo POP, e um aumento significativo da atividade eletromiográfica durante a contração voluntária máxima (CVM) no grupo POP, porém essas variáveis foram menores que as encontradas no grupo sem POP. Em decorrência desses achados, os autores concluíram que a restauração da anatomia pélvica pode explicar a melhora da função e da atividade elétrica dos MAP em pacientes com POP.

Em relação aos desfechos secundários os resultados do presente estudo são amplamente corroborados pela literatura em relação à sintomatologia e impacto do POP na qualidade de vida após a utilização de diversas técnicas cirúrgicas.

O efeito das mudanças anatômicas e funcionais do assoalho pélvico após retopexia robótica e retopexia laparoscópica com malha ventral em uma amostra de 29 mulheres foi verificado por Mäkelä-Kaikkonen et al. (2016) em seu estudo prospectivo randomizado. Os autores avaliaram utilizando os instrumento POP-Q, Ressonância Magnética Defecografia, e os questionários PFDI-20, PFIQ-7 e PSIQ12 antes e 3 meses após a cirurgia. Eles encontraram diferença significativa no POP-Q. A descida anorretal e do colo do útero/cúpula vaginal durante o esforço teve redução significativa de $(-10,4 \pm 14,9 \mathrm{~mm}, \mathrm{p}=0,001$ e $-13.3 \pm 18,1 \mathrm{~mm}, \mathrm{p}<0,001$, respectivamente). A mobilidade dos órgãos pélvicos teve redução significativa dos compartimentos posterior $(-16,6 \pm 20,8 \mathrm{~mm}, \mathrm{p}<0,001)$ e apical $(-13,1 \pm 14,8, p<0,001)$. Nos questionários PFDI-20, PFIQ-7 e PISQ-12 foram observadas mudanças estatisticamente significativas. Não houve diferença significativa entre as duas técnicas cirúrgicas.

O presente estudo contribuiu para uma melhor compreensão do impacto dos POP na função dos MAP e parece ser o primeiro estudo a conduzir uma avaliação clinica da função dos MAP 40 dias após cirurgia para correção do POP.

Algumas limitações deste estudo devem ser elencadas incluindo a ausência de grupo controle, seguimento curto de apenas 40 dias após a cirurgia, falta de acesso a métodos de avaliação por imagem que poderiam trazer informações importantes adicionais. Outro aspecto que deve ser discutido é o fato de que apesar de todas as mulheres terem sido submetidas à cirurgia no mesmo serviço, as cirurgias foram realizadas por diferentes cirurgiões. Apesar disso, o objetivo primário deste estudo não foi avaliar a eficácia da cirurgia na correção do POP. Apesar destas limitações, o estudo utilizou medidas de desfechos válidas e reprodutíveis e todas as avaliações e reavaliações foram conduzidas pela mesma examinadora. 
Estudos futuros com amostras mais amplas deverão fazer um acompanhamento mais longo das participantes e agregar métodos de imagens a avaliação.

\section{Conclusão}

Quanto ao objetivo primário:

- Houve melhora da função muscular após a cirurgia indicada por uma melhora no percentual de mulheres que passaram a contrair corretamente os MAP após a cirurgia, alem melhora na perineometria.

Quanto aos objetivos secundários:

- Houve diminuição da severidade anatômica do POP após a cirurgia.

- Houve melhora da sintomatologia e diminuição do impacto do POP na qualidade de vida após a cirurgia.

- Verificou-se que quanto pior a função dos MAP maior é a sintomatologia do POP e o maior o impacto do POP na qualidade de vida.

- E a maioria das voluntárias declarou-se muito melhor após a cirurgia. 


\section{REFERÊNCIAS}

ABRAMS, P. et al. The standardisation of terminology in lower urinary tract function: report from the standardisation sub-committee of the International Continence Society. Urology, Ridgewood, v. 61, n. 1, p. 37-49, Jan 2003.

ALVAREZ, J.; CVACH, K.; DWYER, P. Complications in pelvic floor surgery. Minerva Ginecol, Torino, v. 65, n. 1, p. 53-67, Feb 2013.

AROUCA, M. A. et al. Validation and cultural translation for Brazilian Portuguese version of the Pelvic Floor Impact Questionnaire (PFIQ-7) and Pelvic Floor Distress Inventory (PFDI-20). Int Urogynecol J, London, Jan 2016.

ASHTON-MILLER, J. A.; DELANCEY, J. O. Functional anatomy of the female pelvic floor. Ann $\mathbf{N} \mathbf{Y}$ Acad Sci, New York , v. 1101, p. 266-96, Apr 2007.

BARBER, M. D. Contemporary views on female pelvic anatomy. Cleve Clin J Med, Cleveland, v. 72 Suppl 4, p. S3-11, Dec 2005.

BARBER, M. D.; MAHER, C. Epidemiology and outcome assessment of pelvic organ prolapse. Int Urogynecol J, London, v. 24, n. 11, p. 1783-90, Nov 2013.

BARBER, M. D. et al. Sexual function in women with urinary incontinence and pelvic organ prolapse. Obstet Gynecol, New York , v. 99, n. 2, p. 281-9, Feb 2002.

BARBER, M. D.; WALTERS, M. D.; BUMP, R. C. Short forms of two condition-specific quality-of-life questionnaires for women with pelvic floor disorders (PFDI-20 and PFIQ-7). Am J Obstet Gynecol, St. Louis, v. 193, n. 1, p. 103-13, Jul 2005.

BLAND, D. R. et al. Use of the Pelvic Organ Prolapse staging system of the International Continence Society, American Urogynecologic Society, and Society of Gynecologic Surgeons in perimenopausal women. Am J Obstet Gynecol, St. Louis, v. 181, n. 6, p. 1324-7; discussion 1327-8, Dec 1999.

$\mathrm{BO}, \mathrm{K}$. Pelvic floor muscle training in treatment of female stress urinary incontinence, pelvic organ prolapse and sexual dysfunction. World J Urol, Berlin, v. 30, n. 4, p. 437-43, Aug 2012.

BRAEKKEN, I. H. et al. Pelvic floor function is independently associated with pelvic organ prolapse. BJOG, Oxford, v. 116, n. 13, p. 1706-14, Dec 2009.

BRAEKKEN, I. H. et al. Can pelvic floor muscle training reverse pelvic organ prolapse and reduce prolapse symptoms? An assessor-blinded, randomized, controlled trial. Am J Obstet Gynecol, St. Louis, v. 203, n. 2, p. 170.e1-7, Aug 2010.

BRUBAKER, L. et al. Surgery for pelvic organ prolapse. Female Pelvic Med Reconstr Surg, Hagerstown, v. 16, n. 1, p. 9-19, Jan 2010.

BUMP, R. C. et al. The standardization of terminology of female pelvic organ prolapse and pelvic floor dysfunction. Am J Obstet Gynecol, St. Louis, v. 175, n. 1, p. 10-7, Jul 1996.

BUMP, R. C.; NORTON, P. A. Epidemiology and natural history of pelvic floor dysfunction. Obstet Gynecol Clin North Am, Philadelphia. 25, n. 4, p. 723-46, Dec 1998.

$\mathrm{B} \varnothing, \mathrm{K}$. Pelvic floor muscle training is effective in treatment of female stress urinary incontinence, but how does it work? Int Urogynecol J Pelvic Floor Dysfunct, Surrey, v. 15, n. 2, p. 76-84, 2004 MarApr 2004.

BØ, K.; FINCKENHAGEN, H. B. Vaginal palpation of pelvic floor muscle strength: inter-test reproducibility and comparison between palpation and vaginal squeeze pressure. Acta Obstet Gynecol Scand, Copenhagen, v. 80, n. 10, p. 883-7, Oct 2001. 
$B \varnothing$, K.; SHERBURN, M. Evaluation of female pelvic-floor muscle function and strength. Phys Ther, Albany, v. 85, n. 3, p. 269-82, Mar 2005.

CHAMOCHUMBI, C. C. et al. Comparison of active and passive forces of the pelvic floor muscles in women with and without stress urinary incontinence. Rev Bras Fisioter, São Carlos, v. 16, n. 4, p. 314-9, 2012 Jul-Aug 2012.

CHEN, X. et al. Pre- and postoperative evaluation of pelvic floor muscle function in POP patiens using surface electromyography and digital palpation. Neurorol Urodyn, New York, v.33, n. 4, p. 403-7, apr 2014.

CHERMANSKY, C. J.; WINTERS, J. C. Complications of vaginal mesh surgery. Curr Opin Urol, London, v. 22, n. 4, p. 287-91, Jul 2012.

CHOW, D.; RODRIGUEZ, L. V. Epidemiology and prevalence of pelvic organ prolapse. Curr Opin Urol, London, v. 23, n. 4, p. 293-8, Jul 2013.

CHRISTENSEN, L. L.; DJURHUUS, J. C.; CONSTANTINOU, C. E. Imaging of pelvic floor contractions using MRI. Neurourol Urodyn, New York, v. 14, n. 3, p. 209-16, 1995.

CLARK, A. L. et al. Epidemiologic evaluation of reoperation for surgically treated pelvic organ prolapse and urinary incontinence. Am J Obstet Gynecol, St. Louis, v. 189, n. 5, p. 1261-7, Nov 2003.

CLIPPINGER, K. Dance anatomy and kinesiology. Champaign: Human Kinetics, 2007.

DELANCEY, J. O. Anatomy and biomechanics of genital prolapse. Clin Obstet Gynecol, Hagerstown, v. 36, n. 4, p. 897-909, Dec 1993.

DELANCEY, J. O. The hidden epidemic of pelvic floor dysfunction: achievable goals for improved prevention and treatment. Am J Obstet Gynecol, St. Louis, v. 192, n. 5, p. 1488-95, May 2005.

DELANCEY, J. O. et al. Graphic integration of causal factors of pelvic floor disorders: an integrated life span model. Am J Obstet Gynecol, St. Louis, v. 199, n. 6, p. 610.e1-5, Dec 2008.

DELANCEY, J. O. et al. Comparison of levator ani muscle defects and function in women with and without pelvic organ prolapse. Obstet Gynecol, New York, v. 109, n. 2 Pt 1, p. 295-302, Feb 2007.

DETOLLENAERE, R. J. et al. [Uterus preserving surgery versus vaginal hysterectomy in treatment of uterine descent: a systematic review]. Ned Tijdschr Geneeskd, Houten, v. 155, n. 42, p. A3623, 2011.

DEVAL, B.; HAAB, F. What's new in prolapse surgery? Curr Opin Urol, London, v. 13, n. 4, p. 31523, Jul 2003.

DEVREESE, A. et al. Incontinent women have altered pelvic floor muscle contraction patterns. J Urol, v. 178, Baltimore, n. 2, p. 558-62, Aug 2007.

DIETZ, H. P.; WILSON, P. D.; CLARKE, B. The use of perineal ultrasound to quantify levator activity and teach pelvic floor muscle exercises. Int Urogynecol J Pelvic Floor Dysfunct, Surrey, v. 12, n. 3, p. 166-8; discussion 168-9, 2001.

DOUGHERTY, M. C.; ABRAMS, R.; MCKEY, P. L. An instrument to assess the dynamic characteristics of the circumvaginal musculature. Nurs Res, New York, v. 35, n. 4, p. 202-6, 1986 JulAug 1986.

DUMOULIN, C.; BOURBONNAIS, D.; LEMIEUX, M. C. Development of a dynamometer for measuring the isometric force of the pelvic floor musculature. Neurourol Urodyn, New York, v. 22, n. 7, p. 64853, 2003.

FABER, K.; FROMER, D. How I Do It: Techniques to avoid complications in transvaginal mesh surgery. Can J Urol, Baie d'Urfé, v. 22, n. 3, p. 7844-6, Jun 2015. 
FERREIRA, C. H. et al. Inter-rater reliability study of the modified Oxford Grading Scale and the Peritron manometer. Physiotherapy, London, v. 97, n. 2, p. 132-8, Jun 2011.

FRAWLEY, H. C. et al. Reliability of pelvic floor muscle strength assessment using different test positions and tools. Neurourol Urodyn, New York, v. 25, n. 3, p. 236-42, 2006.

FRAWLEY, H. C. et al. Physiotherapy as an adjunct to prolapse surgery: an assessor-blinded randomized controlled trial. Neurourol Urodyn, New York, v. 29, n. 5, p. 719-25, Jun 2010.

GHETTI, C. et al. Severity of pelvic organ prolapse associated with measurements of pelvic floor function. Int Urogynecol J Pelvic Floor Dysfunct, Surrey, v. 16, n. 6, p. 432-6, 2005 Nov-Dec 2005.

GUNNARSSON, M.; MATTIASSON, A. Circumvaginal surface electromyography in women with urinary incontinence and in healthy volunteers. Scand J Urol Nephrol Suppl, Stockholm, v. 157, p. 89-95, 1994.

HAGEN, S.; STARK, D. Conservative prevention and management of pelvic organ prolapse in women. Cochrane Database Syst Rev, Oxford, n. 12, p. Cd003882, 2011.

HAGEN, S. et al. Individualised pelvic floor muscle training in women with pelvic organ prolapse (POPPY): a multicentre randomised controlled trial. Lancet, London, v. 383, n. 9919, p. 796-806, Mar 2014.

HAHN, I.; OHLSSON, B.; LINDSTRØM, S. Pelvic elevation force: a new technique to assess pelvic floor function. Neurourol Urodyn, New York, v. 10, p. 396-397, 1991.

HALLOCK, J. L.; HANDA, V. L. The Epidemiology of Pelvic Floor Disorders and Childbirth: An Update. Obstet Gynecol Clin North Am, Philadelphia v. 43, n. 1, p. 1-13, Mar 2016.

HAYLEN, B. T. et al. An International Urogynecological Association (IUGA)/International Continence Society (ICS) joint report on the terminology for female pelvic floor dysfunction. Neurourol Urodyn, New York, v. 29, n. 1, p. 4-20, 2010.

HAYLEN, B. T. et al. An International Urogynecological Association (IUGA) / International Continence Society (ICS) joint report on the terminology for female pelvic organ prolapse (POP). Int Urogynecol J, London, v. 27, n. 2, p. 165-94, Feb 2016.

HERBISON, G. P.; DEAN, N. Weighted vaginal cones for urinary incontinence. Cochrane Database Syst Rev, Copenhagen, v. 7, p. CD002114, 2013.

JARVIS, S. K. et al. Peri-operative physiotherapy improves outcomes for women undergoing incontinence and or prolapse surgery: results of a randomised controlled trial. Aust $\mathbf{N} \mathbf{Z}$ J Obstet Gynaecol, Melbourne, v. 45, n. 4, p. 300-3, Aug 2005.

JELOVSEK, J. E.; BARBER, M. D. Women seeking treatment for advanced pelvic organ prolapse have decreased body image and quality of life. Am J Obstet Gynecol, St. Louis , v. 194, n. 5, p. 1455-61, May 2006.

JELOVSEK, J. E.; MAHER, C.; BARBER, M. D. Pelvic organ prolapse. Lancet, London, v. 369, n. 9566, p. 1027-38, Mar 242007.

KARRAM, M.; MAHER, C. Surgery for posterior vaginal wall prolapse. Int Urogynecol J, London, v. 24, n. 11, p. 1835-41, Nov 2013.

KEGEL, A. H. Progressive resistance exercise in the functional restoration of the perineal muscles. Am J Obstet Gynecol, St. Louis, v. 56, n. 2, p. 238-48, Aug 1948.

KIM, C. M. et al. Risk factors for pelvic organ prolapse. Int J Gynaecol Obstet, New York, v. 98, n. 3, p. 248-51, Sep 2007.

KRISSI, H. et al. Risk factors for recurrence after Le Fort colpocleisis for severe pelvic organ prolapse in elderly women. Int J Surg, London, v. 20, p. 75-9, Aug 2015. 
LAKEMAN, M. M. et al. Peri-operative physiotherapy to prevent recurrent symptoms and treatment following prolapse surgery: supported by evidence or not? Int Urogynecol J, London, v. 24, n. 3, p. 371-5, Mar 2013.

LAYCOCK, J.; JERWOOD, D. Pelvic floor muscle assessment: The PERFECT scheme.

Physiotherapy, London, v. 87, n. 12, p. 631-642, 2001.

LOVATSIS, D.; DRUTZ, H. P. Safety and efficacy of sacrospinous vault suspension. Int Urogynecol J Pelvic Floor Dysfunct, Surrey, v. 13, n. 5, p. 308-13, 2002.

LUNARDELLI, J. L. et al. Polypropylene mesh vs. site-specific repair in the treatment of anterior vaginal wall prolapse: preliminary results of a randomized clinical trial. Rev Col Bras Cir, Rio de Janeiro, v. 36, n. 3, p. 210-6, Jul 2009.

MAHER, C. et al. Surgical management of pelvic organ prolapse in women. Cochrane Database Syst Rev, Oxford, n. 4, p. CD004014, 2010. I

MAHER, C. et al. Surgical management of pelvic organ prolapse in women. Cochrane Database Syst Rev, Oxford, v. 4, p. Cd004014, 2013.

MAWAJDEH, S. M.; AL-QUTOB, R. J.; FARAG, A. M. Prevalence and risk factors of genital prolapse. A multicenter study. Saudi Med J, Riyadh, v. 24, n. 2, p. 161-5, Feb 2003.

MCLENNAN, M. T. et al. Family history as a risk factor for pelvic organ prolapse. Int Urogynecol J Pelvic Floor Dysfunct, Surrey, v. 19, n. 8, p. 1063-9, Aug 2008.

MESSELINK, B. et al. Standardization of terminology of pelvic floor muscle function and dysfunction: report from the pelvic floor clinical assessment group of the International Continence Society.

Neurourol Urodyn, v. 24, n. 4, p. 374-80, 2005.

MODEL, A. N.; SHEK, K. L.; DIETZ, H. P. Levator defects are associated with prolapse after pelvic floor surgery. Eur J Obstet Gynecol Reprod Biol, Amsterdam, v. 153, n. 2, p. 220-3, Dec 2010.

MORGAN, D. M. et al. Vaginal support as determined by levator ani defect status 6 weeks after primary surgery for pelvic organ prolapse. Int J Gynaecol Obstet, New Ypork, v. 114, n. 2, p. 141-4, Aug 2011.

MORGAN, D. M. et al. Urethral sphincter morphology and function with and without stress incontinence. J Urol, Baltimore, v. 182, n. 1, p. 203-9, Jul 2009.

MORIN, M. et al. Pelvic floor muscle function in continent and stress urinary incontinent women using dynamometric measurements. Neurourol Urodyn, New York, v. 23, n. 7, p. 668-74, 2004.

MUIR, T. W.; STEPP, K. J.; BARBER, M. D. Adoption of the pelvic organ prolapse quantification system in peer-reviewed literature. Am J Obstet Gynecol, St. Louis, v. 189, n. 6, p. 1632-5; discussion 1635-6, Dec 2003.

MÄKELÄ-KAIKKONEN, J. K. et al. Anatomical and functional changes to the pelvic floor after robotic versus laparoscopic ventral rectopexy: a randomised study. Int Urogynecol J, London, Jun 2016.

NYGAARD, I. et al. Prevalence of symptomatic pelvic floor disorders in US women. JAMA, Chicago, v. 300, n. 11, p. 1311-6, Sep 2008.

OLSEN, A. L. et al. Epidemiology of surgically managed pelvic organ prolapse and urinary incontinence. Obstet Gynecol, New York, v. 89, n. 4, p. 501-6, Apr 1997.

OVERSAND, S. $\mathrm{H}$. et al. The association between different measures of pelvic floor muscle function and female pelvic organ prolapse. Int Urogynecol J, London, v. 26, n. 12, p. 1777-81, Dec 2015.

PARK, A. J.; PARAISO, M. F. Surgical management of uterine prolapse. Minerva Ginecol, Torino, v. 60, n. 6, p. 493-507, Dec 2008. 
PAULS, R. N. et al. Sexual function in patients presenting to a urogynecology practice. Int Urogynecol J Pelvic Floor Dysfunct, Surrey, v. 17, n. 6, p. 576-80, Nov 2006.

PERSU, C. et al. Pelvic Organ Prolapse Quantification System (POP-Q) - a new era in pelvic prolapse staging. J Med Life, Bucharest, v. 4, n. 1, p. 75-81, 2011 Jan-Mar 2011.

PETROS, P. E. Vault prolapse II: Restoration of dynamic vaginal supports by infracoccygeal sacropexy, an axial day-case vaginal procedure. Int Urogynecol J Pelvic Floor Dysfunct, Surrey, v. 12, n. 5, p. 296-303, 2001.

PHAM, T. et al. New pelvic symptoms are common after reconstructive pelvic surgery. Am J Obstet Gynecol, St. Louis, v. 200, n. 1, p. 88.e1-5, Jan 2009.

PODNAR, S.; VODUSEK, D. B. Protocol for clinical neurophysiologic examination of the pelvic floor. Neurourol Urodyn, New York, v. 20, n. 6, p. 669-82, 2001.

ROCCA ROSSETTI, S. Functional anatomy of pelvic floor. Arch Ital Urol Androl, Milano, v. 88, n. 1, p. 28-37, Mar 2016.

SALA, F. et al. Neurophysiology of complex spinal cord untethering. J Clin Neurophysiol, New York, v. 31, n. 4, p. 326-36, Aug 2014.

SAMUELSSON, E. C. et al. Signs of genital prolapse in a Swedish population of women 20 to 59 years of age and possible related factors. Am J Obstet Gynecol, St. Louis, v. 180, n. 2 Pt 1, p. 299 305, Feb 1999.

SCARABOTTO, L. B.; RIESCO, M. L. Factors related to perineal trauma in normal births in nulliparous. Rev Esc Enferm USP, São Paulo, v. 40, n. 3, p. 389-95, Sep 2006.

SHISHIDO, K. et al. Influence of pelvic floor muscle contraction on the profile of vaginal closure pressure in continent and stress urinary incontinent women. J Urol, Baltimore, v. 179, n. 5, p. 191722, May 2008. ISSN 1527-3792.

SLIEKER-TEN HOVE, M. et al. Pelvic floor muscle function in a general population of women with and without pelvic organ prolapse. Int Urogynecol J, London, v. 21, n. 3, p. 311-9, Mar 2010.

SMITH, F. J. et al. Lifetime risk of undergoing surgery for pelvic organ prolapse. Obstet Gynecol, New York, v. 116, n. 5, p. 1096-100, Nov 2010.

STÜPP, L. et al. Pelvic floor muscle training for treatment of pelvic organ prolapse: an assessorblinded randomized controlled trial. Int Urogynecol J, London, v. 22, n. 10, p. 1233-9, Oct 2011.

SUBAK, L. L. et al. Cost of pelvic organ prolapse surgery in the United States. Obstet Gynecol, New York, v. 98, n. 4, p. 646-51, Oct 2001.

THIAGAMOORTHY, G. et al. Management of prolapse in older women. Post Reprod Health, Los Angeles, v. 20, n. 1, p. 30-35, Mar 2014.

WANG, L. et al. The improvement of pelvic floor muscle function in POP patients after the Prolift procedure: results from surface electromyography. Int Urogynecol J, London, v. 24, n. 10, p. 1703-8, Oct 2013.

WARWICK, R.; WILLIAMS, P. Gray's anatomy. 35th. Edinburgh: Longman, 1973.

WEBER, A. M. et al. Anterior colporrhaphy: a randomized trial of three surgical techniques. Am J Obstet Gynecol, St.Louis, v. 185, n. 6, p. 1299-304; discussion 1304-6, Dec 2001.

WIEGERSMA, M. et al. Effect of pelvic floor muscle training compared with watchful waiting in older women with symptomatic mild pelvic organ prolapse: randomised controlled trial in primary care. BMJ, London, v. 349, p. g7378, 2014.

YALCIN, I.; BUMP, R. C. Validation of two global impression questionnaires for incontinence. Am J Obstet Gynecol, St. Louis, v. 189, n. 1, p. 98-101, Jul 2003. 
ZACHARIN, R. F. Pulsion enterocele: review of functional anatomy of the pelvic floor. Obstet Gynecol, New York, v. 55, n. 2, p. 135-40, Feb 1980. 


\section{ANEXOS \\ ANEXO A - APROVAÇÃO DO COMITÊ DE ÉTICA EM PESQUISA}

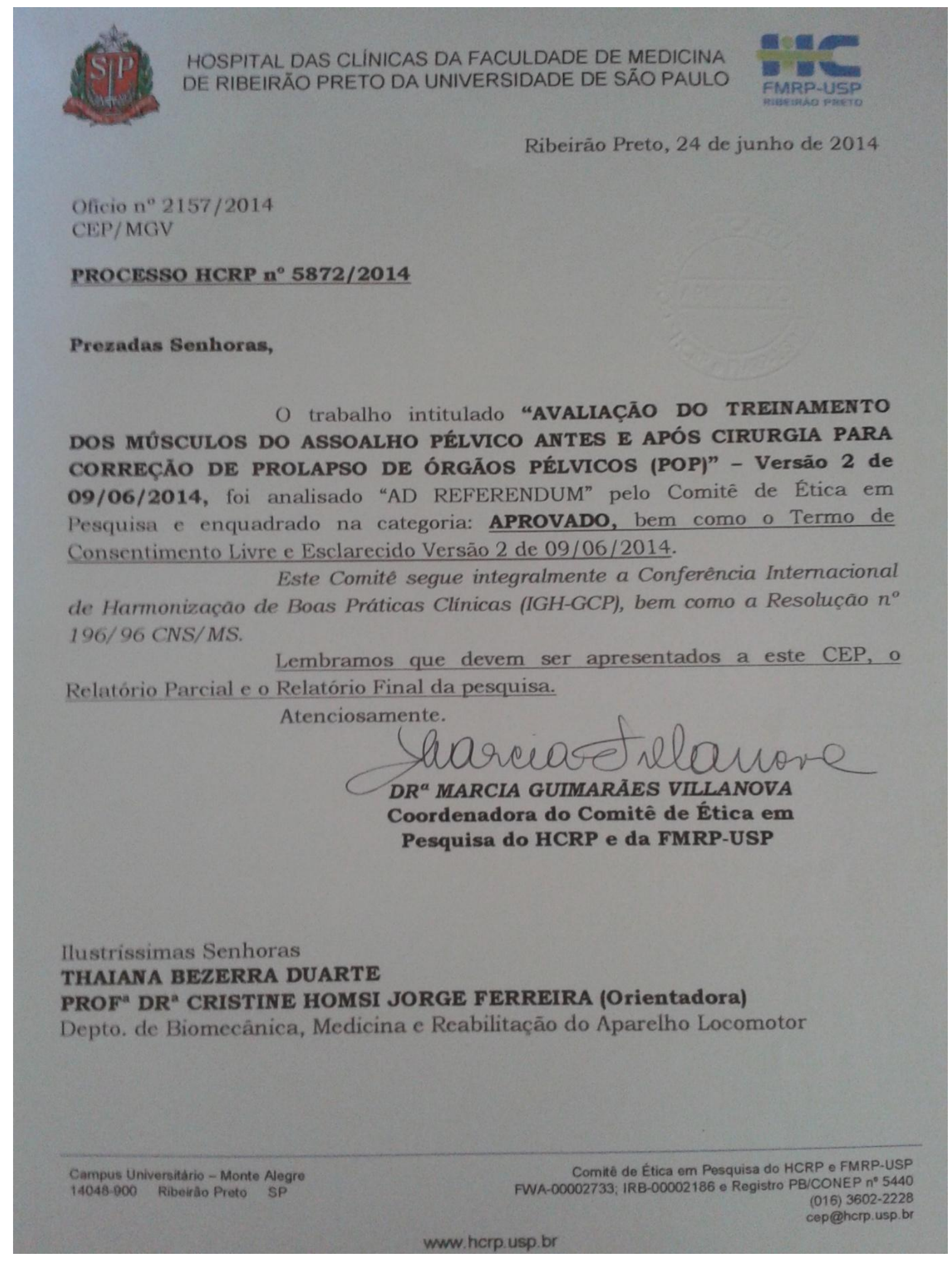




\section{ANEXO B - TERMO DE CONSENTIMENTO LIVRE E ESCLARECIDO}

NOME DA PESQUISA: "Avaliação do treinamento dos músculos do assoalho pélvico antes e após cirurgia para correção de prolapso de órgãos pélvicos (POP): ensaio clínico randomizado".

Pesquisadores responsáveis: Cristine Homsi Jorge Ferreira, Thaiana Bezerra Duarte e Luiz Gustavo Oliveira Brito.

Você está sendo convidada a participar da pesquisa "Avaliação do treinamento dos músculos do assoalho pélvico antes e após cirurgia para correção de prolapso de órgãos pélvicos (POP): ensaio clínico randomizado"

\section{O que é a pesquisa? Qual é o seu objetivo?}

O prolapso de órgãos pélvicos é a descida dos órgãos que se encontram na região pélvica (útero, bexiga e intestino) em direção à vagina. Ele ocorre quando os ligamentos e músculos que prendem esses órgãos em seus locais se enfraquecem. Normalmente ele é causado pela gravidez e pelo parto. Mas também pode acontecer devido a outros fatores que aumentam a pressão dentro da sua barriga (obesidade, problemas respiratórios como tosse crônica, intestino preso e câncer de algum órgão pélvico) ou após histerectomia (cirurgia pra retirada de útero).

O prolapso de órgãos pélvicos é uma condição muito comum, principalmente em mulheres maiores de quarenta anos. Estima-se que metade das mulheres que têm filhos vão experimentar algum tipo de prolapso em anos posteriores.

O prolapso de órgãos pélvico pode afetar a vida diária das mulheres que sofrem desta condição, diminuindo sua capacidade física ou sexual, fazendo com que a mulher tenha perda de urina. Embora o prolapso não seja considerado uma condição que envolve risco de vida, pode causar incômodo e angústia.

O objetivo deste estudo é avaliar a eficiência de um programa de exercícios para fortalecimento dos músculos do períneo associado à cirurgia para correção do prolapso de órgãos pélvicos. Queremos verificar se esses exercícios e a cirurgia trazem melhora nos sintomas sentidos por você, como perda de urina, diminuição na função sexual e comprometimento na sua qualidade de vida.

\section{Quais são as etapas da pesquisa?}

Após ser qualificada para o estudo, você irá responder a quatro questionários contendo perguntas a respeito do impacto do prolapso e da perda de urina na sua qualidade de vida e na sua função sexual, se você tiver, além da sua percepção sobre o tratamento que está sendo realizado. Depois você será submetida a uma avaliação da força dos músculos do seu períneo.

Para isso será realizado o toque vaginal (parecido com o que você faz com o ginecologista) e utilizado um aparelho na vagina para verificar sua força de contração da vagina. Para isso, vamos introduzir um pequeno aparelho na sua vagina, o que não vai the causar dor, apenas um desconforto na vagina e você irá apertá-lo com o músculo do períneo. Vamos também introduzir um espéculo na 
vagina para medir o quanto sua bexiga, útero ou reto estão descidos. Esse espéculo pode causar dor na primeira avaliação pós-cirurgia.

Essas avaliações serão feitas 2 semanas antes da cirurgia, um dia antes da cirurgia para correção do prolapso, 40 e 90 dias após a cirurgia.

Você poderá ser sorteada para participar do grupo de exercícios para fortalecimento dos músculos do seu períneo. Contudo, algumas mulheres desta pesquisa após o sorteio, cairão no grupo das que não farão os exercícios, mas receberão informações sobre eles ao final do estudo e poderão receber tratamento ao final da pesquisa, se assim desejarem. Estes exercícios serão na posição em pé, sentada, em posição de gata e deitada para que você aprenda a contrair os músculos do períneo. Serão feitos duas vezes por semana, 15 dias antes da cirurgia e uma vez a cada 15 dias durante três meses após o procedimento cirúrgico.

Você também será orientada a realizar as contrações do períneo em casa três vezes por semana antes e após a cirurgia.

\section{Quais são os efeitos colaterais do tratamento? 0 que devo fazer se eu tiver qualquer problema?}

Os exercícios de contração da musculatura do períneo não the causarão nenhum risco ou dor durante sua realização. Na primeira avaliação no pós-operatório, pode haver dor quando for usado o espéculo e/ou o aparelho que infla na vagina. Assim que terminarmos a avaliação, o incômodo passará. Caso perdure, entre em contato imediatamente com nossa equipe.

Caso você não aceite participar, receberá se houver necessidade, tratamento da mesma maneira.

Caso você tenha algum problema durante o estudo, a equipe de pesquisadores que coordena este estudo estará apta a solucionar seu problema e/ou dúvida.

\section{O que acontece se eu não quiser participar da pesquisa ou desistir durante a realização da mesma?}

As pacientes que não quiserem assinar o termo de consentimento estarão automaticamente excluídas do trabalho, porém não deixarão de ser atendidas nos ambulatórios.

Não haverá recompensa financeira para os voluntários que participarem do estudo. Na eventualidade de que qualquer paciente venha a necessitar de quaisquer tratamentos durante ou após a realização do estudo, e a este relacionados, estes serão fornecidos gratuitamente, sob nossa responsabilidade. Caso ocorram despesas relativas a transporte e alimentação estas serão pagas pelo pesquisador responsável.

Com essa pesquisa, os benefícios não são só para você, mas poderão melhorar a qualidade de vida de muitas outras pacientes no futuro. 
$\mathrm{Eu}$,

abaixo assinada, tendo recebido as informações acima, e ciente dos meus direitos abaixo relacionados, concordo em participar do presente estudo:

* A garantia de receber a resposta a qualquer pergunta ou esclarecimento a qualquer dúvida acerca dos procedimentos, riscos, benefícios e outros relacionados com a pesquisa e o tratamento a que serei submetida;

* A liberdade de retirar o meu consentimento a qualquer momento e deixar de participar do estudo, sem que isso traga prejuízo à continuação do meu cuidado e tratamento;

* A segurança de que não serei identificada e de que será mantido o caráter confidencial da informação relacionada com a minha privacidade;

* O compromisso de que me serão fornecidas informações atualizadas durante o estudo, ainda que estas possam afetar a minha vontade de continuar participando;

* Que se existirem gastos adicionais, estes serão absorvidos pelo orçamento da pesquisa.

Tenho ciência do exposto acima eu desejo realizar a técnica de fisioterapia como método terapêutico recomendado pela equipe que subscreve este documento.

Ribeirão Preto '

Assinatura do Pesquisador

\section{PESQUISADORES RESPONSÁVEIS:}

Ft. Thaiana Bezerra Duarte

Dra. Cristine Homsi Jorge Ferreira

Dr. Luiz Gustavo Oliveira Brito

Telefones de contato: (16)3602-2311 (Ambulatório de Uroginecologia, segundas, quartas, quintas à tarde, das 13 às 17 horas) e (16)3602-0741 (Laboratório de Avaliação Funcional do Assoalho Pélvicosegunda à sexta das 8:00 às 12:00 horas). (16) 982419816 (todos os dias horário integral). 


\section{ANEXO C - FICHA PROTOCOLO}

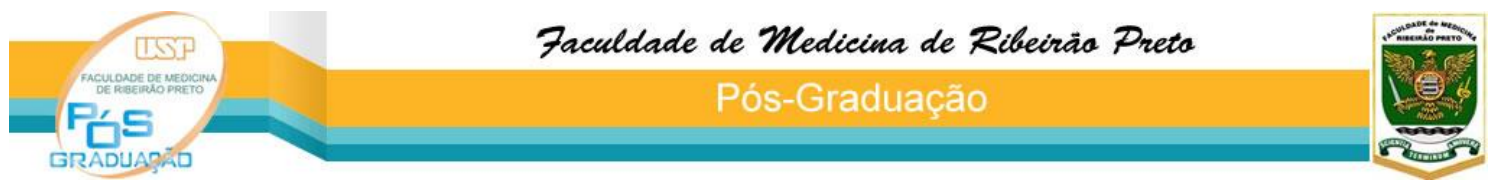

Nome Prontuário

Data Nascimento Idade

Profissão Etnia

Estado civil Telefone Escolaridade

Endereço Renda familiar

G: $P:$ A: Tipos parto Episiotomia ( ) sim ( ) não DUM

Peso do maior RN: parto: Peso Altura IMC dade do Primeiro parto Idade último Regularidade menstrual ( ) sim ( ) não ( ) não se aplica Tabagismo ( ) sim ( ) não Etilismo ( ) sim ( ) não Ativ. Física passado não Ativ. Física presente ( ) sim ( ) não Conhece TMAP: ( ) sim ( )não Já realizou TMAP ( ) sim ( ) não Função sexual ( ) sim （ ) não Frequência da atividade sexual Idade do primeiro coito: Quanto tempo está com parceiro:

Cirurgias prévias Comorbidades

Data cirurgia:

\section{Visita 1: 15 dias antes da cirurgia}

Sorteada para qual grupo? TMAP ou não-TMAP

- Exame Físico

Presença de Cicatriz: ( ) sim ( ) não

POP-Q

\begin{tabular}{r|r|r} 
Aa & Ba & C \\
\hline hg & Cp & cvt \\
\hline Ap & $\mathrm{Bp}$ & D
\end{tabular}


AFA: Grau

Perineômetro: $1^{\underline{a}}$ medida: Média Duração Pico

2ª medida: Média Duração Pico

$3^{\text {a }}$ medida: Média Duração Pico

- Aplicação dos questionários

Pelvic Floor Distress Inventory (PFDI-20)

Pelvic Floor Impact Questionnaire (PFIQ-7)

Patient Global Impression of Improvement (PGI-I)

\section{Visita 2: 1 dia antes da cirurgia}

\section{- Exame Físico}

POP-Q

\begin{tabular}{r|r|r}
$\mathrm{Aa}$ & $\mathrm{Ba}$ & $\mathrm{C}$ \\
\hline $\mathrm{hg}$ & $\mathrm{Cp}$ & $\mathrm{cvt}$ \\
\hline $\mathrm{Ap}$ & $\mathrm{Bp}$ & $\mathrm{D}$
\end{tabular}

AFA: Grau

Perineômetro: $1^{\text {a }}$ medida: Média Duração

Pico

$2^{\underline{a}}$ medida: Média Duração Pico

3aㅡ medida: Média Duração Pico

\section{- Aplicação dos questionários}

Pelvic Floor Distress Inventory (PFDI-20)

Pelvic Floor Impact Questionnaire (PFIQ-7)

Patient Global Impression of Improvement (PGI-I)

\section{Visita 3: 40 dias após a cirurgia}

- Exame Físico

POP-Q

\begin{tabular}{r|r|r} 
Aa & Ba & C \\
\hline hg & $\mathrm{Cp}$ & cvt \\
\hline $\mathrm{Ap}$ & $\mathrm{Bp}$ & $\mathrm{D}$
\end{tabular}


AFA: Grau

Perineômetro: $1^{\mathfrak{a}}$ medida: Média Duração Pico

$2^{\text {a }}$ medida: Média Duração Pico

3ํㅡㄹ medida: Média Duração Pico

- Aplicação dos questionários

Pelvic Floor Distress Inventory (PFDI-20)

Pelvic Floor Impact Questionnaire (PFIQ-7)

Patient Global Impression of Improvement (PGI-I)

- Visita 4: 90 dias após a cirurgia Exame Físico

POP-Q

\begin{tabular}{r|r|r} 
Aa & Ba & C \\
\hline hg & $\mathrm{Cp}$ & cvt \\
\hline $\mathrm{Ap}$ & $\mathrm{Bp}$ & $\mathrm{D}$
\end{tabular}

AFA: Grau

Perineômetro: $1^{\underline{a}}$ medida: Média Duração Pico $2^{\underline{a}}$ medida: Média Duração Pico 3ª medida: Média Duração Pico

- Aplicação dos questionários

Pelvic Floor Distress Inventory (PFDI-20)

Pelvic Floor Impact Questionnaire (PFIQ-7)

Patient Global Impression of Improvement (PGI-I) 


\section{ANEXO D - PELVIC FLOOR DISTRESS INVENTORY (PFDI - 20)}

\section{INSTRUÇÕES}

Por favor, responda a todas as perguntas do seguinte questionário. Essas questões serão para saber se você tem alguns sintomas intestinais, vesicais (bexiga) ou pélvicos e o quanto eles incomodam você. Responda cada quesito com um $X$ no local apropriado. Se você não tem certeza como responder a questão, dê a melhor resposta que você puder. Enquanto responde as questões, por favor considere os sintomas dos últimos 3 meses.

NOME

DATA

1 - Você geralmente sente uma pressão na parte de baixo do abdômen?
( ) $\operatorname{Sim}$
( ) Não

Se sim, o quanto isso incomoda você?
( ) 1
( ) 2
( ) 3
( ) 4

Nada Um pouco Moderadamente Bastante

2 - Você geralmente sente peso na região pélvica?
( ) $\operatorname{Sim}$
( ) Não

Se sim, o quanto isso incomoda você?
( ) 1
( ) 2
( ) 3
( ) 4

Nada Um pouco Moderadamente Bastante

3 - Você geralmente vê ou sente algo saindo pela vagina?
( ) Sim
( ) Não

Se sim, o quanto isso incomoda você?
( ) 1
( ) 2
( ) 3
( ) 4

Nada Um pouco Moderadamente Bastante

4 - Você geralmente tem de empurrar a vagina ou ao redor do reto para defecar completamente?
( ) $\operatorname{Sim}$
( ) Não

Se sim, o quanto isso incomoda você?
( ) 1
( ) 2
( ) 3
( ) 4

Nada Um pouco Moderadamente Bastante

5 - Você geralmente sente que sua bexiga não esvaziou completamente após urinar?
( ) Sim
( ) Não

Se sim, o quanto isso incomoda você?
( ) 1
( ) 2
( ) 3
( ) 4 
Nada Um pouco Moderadamente Bastante

6 - Você já teve de empurrar a região da bexiga com seus dedos para começar ou completar o ato urinário?

( ) $\operatorname{Sim}$

Se sim, o quanto isso incomoda você?
( ) 1
( ) 2
( ) 3
( ) 4

Nada Um pouco Moderadamente Bastante

7 - Você sente que precisa fazer muita força para defecar?
( ) $\operatorname{Sim}$
( ) Não

Se sim, o quanto isso incomoda você?
( ) 1
( ) 2
( ) 3
( ) 4

Nada Um pouco Moderadamente Bastante

8 - Você sente que seu intestino não esvazia completamente ao final da defecação?
( ) Sim
( ) Não

Se sim, o quanto isso incomoda você?
( ) 1
( ) 2
( ) 3
( ) 4

Nada Um pouco Moderadamente Bastante

9 - Você geralmente perde fezes sem controle quando tem vontade de defecar?
( ) $\operatorname{Sim}$
( ) Não

Se sim, o quanto isso incomoda você?
( ) 1
( ) 2
( ) 3
( ) 4

Nada Um pouco Moderadamente Bastante

10 - Você geralmente perde fezes sem controle quando suas fezes estão líquidas ou ralas?

( ) $\operatorname{Sim}$ ( ) Não

Se sim, o quanto isso incomoda você?
( ) 1
( ) 2
( ) 3
( ) 4

Nada Um pouco Moderadamente Bastante

11 - Você geralmente perde gazes pelo reto sem seu controle?

( ) $\operatorname{Sim}$ ( ) Não

Se sim, o quanto isso incomoda você?
( ) 1
( ) 2
( ) 3
( ) 4

Nada Um pouco Moderadamente Bastante

12 - Você geralmente sente dor ao defecar?
( ) $\operatorname{Sim}$
( ) Não

Se sim, o quanto isso incomoda você? 

( ) 1
( ) 2
( ) 3
( ) 4

Nada Um pouco Moderadamente Bastante

13 - Você geralmente tem uma forte sensação de urgência e tem de sair correndo para ir ao banheiro para defecar?
( ) $\operatorname{Sim}$
( ) Não

Se sim, o quanto isso incomoda você?
( ) 1
( ) 2
( ) 3
( ) 4

Nada Um pouco Moderadamente Bastante

14 - Alguma parte do seu intestino passa pelo reto e se exterioriza durante ou após defecar?

( ) $\operatorname{Sim}$ ( ) Não

Se sim, o quanto isso incomoda você?
( ) 1
( ) 2
( ) 3
( ) 4

Nada Um pouco Moderadamente Bastante

15 - Você geralmente tem micções frequente?
( ) $\operatorname{Sim}$
( ) Não

Se sim, o quanto isso incomoda você?
( ) 1
( ) 2
( ) 3
( ) 4
Nada Um pouco Moderadamente Bastante

16 - Você geralmente tem perda de urina associada com a sensação de urgência: isto é, uma forte necessidade de ir ao banheiro?
( ) Sim
( ) Não

Se sim, o quanto isso incomoda você?
( ) 1
( ) 2
( ) 3
( ) 4
Nada Um pouco Moderadamente Bastante

17 - Você geralmente perde urina durante a tosse, espirro ou risada?
( ) $\operatorname{Sim}$
( ) Não

Se sim, o quanto isso incomoda você?
( ) 1
( ) 2
( ) 3
( ) 4

Nada Um pouco Moderadamente Bastante

18 - Você geralmente perde pequenas quantidade de urina (gotas)?
( ) Sim
( ) Não

Se sim, o quanto isso incomoda você?
( ) 1
( ) 2
( ) 3
( ) 4

Nada Um pouco Moderadamente Bastante 
19 - Você geralmente tem dificuldade para esvaziar bexiga?
( ) Sim
( ) Não

Se sim, o quanto isso incomoda você?
( ) 1
( ) 2
( ) 3
( ) 4

Nada

Um pouco

Moderadamente

Bastante

20 - Você geralmente sente dor ou desconforto na parte de baixo do abdômen ou regiã genital?
( ) $\operatorname{Sim}$
( ) Não

Se sim, o quanto isso incomoda você?
( ) 1
( ) 2
( ) 3
( ) 4
Nada Um pouco Moderadamente
Bastante

Obrigado por dedicar seu tempo para responder este questionário. 


\section{ANEXO E - PELVIC FLOOR IMPACT QUESTIONNAIRE (PFIQ - 7)}

PELVIC FLOOR IMPACT QUESSTIONNAIRE - 7 Nome: Data

Instruções: Algumas mulheres acham que sintomas vesicais (bexiga), intestinais e vaginais afetam suas atividades, relacionamentos e sentimento. Para cada questão, marque um $\mathrm{X}$ na resposta que melhor descreve o quanto suas atividades, relacionamentos e sentimentos estão sendo afetados por seus sintomas ou condições vesicais, intestinais e vaginais nos últimos 3 meses. Por favor, certifique-se de que você marcou uma resposta em todas as $\mathbf{3}$ colunas relativas a cada pergunta.

\begin{tabular}{|c|c|c|c|}
\hline $\begin{array}{l}\text { Como os sintomas ou condições a } \\
\text { seguir afetam seu (s)/sua (s): }\end{array}$ & Bexiga ou urina & Intestino ou reto & Vagina ou pélvis \\
\hline $\begin{array}{l}1 \text { - Capacidade de fazer atividades } \\
\text { domésticas (cozinhar, lavar. limpar } \\
\text { a casa)? }\end{array}$ & $\begin{array}{l}\text { ( ) Nada } \\
\text { ( ) Um pouco } \\
\text { ( ) Moderadamente } \\
\text { ( ) Bastante }\end{array}$ & $\begin{array}{l}\text { ( ) Nada } \\
\text { ( ) Um pouco } \\
\text { ( ) Moderadamente } \\
\text { ( ) Bastante }\end{array}$ & $\begin{array}{l}\text { ( ) Nada } \\
\text { ( ) Um pouco } \\
\text { ( ) Moderadamente } \\
\text { ( ) Bastante }\end{array}$ \\
\hline $\begin{array}{l}2 \text { - Capacidade para fazer } \\
\text { atividades físicas como caminhada, } \\
\text { natação ou outros exercícios? }\end{array}$ & $\begin{array}{l}\text { ( ) Nada } \\
\text { ( ) Um pouco } \\
\text { ( ) Moderadamente } \\
\text { ( ) Bastante }\end{array}$ & $\begin{array}{l}\text { ( ) Nada } \\
\text { ( ) Um pouco } \\
\text { ( ) Moderadamente } \\
\text { ( ) Bastante }\end{array}$ & $\begin{array}{l}\text { ( ) Nada } \\
\text { ( ) Um pouco } \\
\text { ( ) Moderadamente } \\
\text { ( ) Bastante }\end{array}$ \\
\hline $\begin{array}{l}3 \text { - Atividades de entretenimento } \\
\text { como ir ao cinema ou ao teatro? }\end{array}$ & $\begin{array}{l}\text { ( ) Nada } \\
\text { ( ) Um pouco } \\
\text { ( ) Moderadamente } \\
\text { ( ) Bastante }\end{array}$ & $\begin{array}{l}\text { ( ) Nada } \\
\text { ( ) Um pouco } \\
\text { ( ) Moderadamente } \\
\text { ( ) Bastante }\end{array}$ & $\begin{array}{l}\text { ( ) Nada } \\
\text { ( ) Um pouco } \\
\text { ( ) Moderadamente } \\
\text { ( ) Bastante }\end{array}$ \\
\hline $\begin{array}{l}4 \text { - Capacidade de viajar de carro } \\
\text { ou ônibus por distâncias mas longe } \\
\text { que } 30 \text { minutos de sua casa? }\end{array}$ & $\begin{array}{l}\text { ( ) Nada } \\
\text { ( ) Um pouco } \\
\text { ( ) Moderadamente } \\
\text { ( ) Bastante }\end{array}$ & $\begin{array}{l}\text { ( ) Nada } \\
\text { ( ) Um pouco } \\
\text { ( ) Moderadamente } \\
\text { ( ) Bastante }\end{array}$ & $\begin{array}{l}\text { ( ) Nada } \\
\text { ( ) Um pouco } \\
\text { ( ) Moderadamente } \\
\text { ( ) Bastante }\end{array}$ \\
\hline $\begin{array}{l}5 \text { - Participação em atividades fora } \\
\text { de casa? }\end{array}$ & $\begin{array}{l}\text { ( ) Nada } \\
\text { ( ) Um pouco } \\
\text { ( ) Moderadamente } \\
\text { ( ) Bastante }\end{array}$ & $\begin{array}{l}\text { ( ) Nada } \\
\text { ( ) Um pouco } \\
\text { ( ) Moderadamente } \\
\text { ( ) Bastante }\end{array}$ & $\begin{array}{l}\text { ( ) Nada } \\
\text { ( ) Um pouco } \\
\text { ( ) Moderadamente } \\
\text { ( ) Bastante }\end{array}$ \\
\hline $\begin{array}{l}6 \text { - Saúde emocional (nervosismo, } \\
\text { depressão, outras)? }\end{array}$ & $\begin{array}{l}\text { ( ) Nada } \\
\text { ( ) Um pouco } \\
\text { ( ) Moderadamente } \\
\text { ( ) Bastante }\end{array}$ & $\begin{array}{l}\text { ( ) Nada } \\
\text { ( ) Um pouco } \\
\text { ( ) Moderadamente } \\
\text { ( ) Bastante }\end{array}$ & $\begin{array}{l}\text { ( ) Nada } \\
\text { ( ) Um pouco } \\
\text { ( ) Moderadamente } \\
\text { ( ) Bastante }\end{array}$ \\
\hline 7 - Sentimento de frustração? & $\begin{array}{l}\text { ( ) Nada } \\
\text { ( ) Um pouco } \\
\text { ( ) Moderadamente } \\
\text { ( ) Bastante }\end{array}$ & $\begin{array}{l}\text { ( ) Nada } \\
\text { ( ) Um pouco } \\
\text { ( ) Moderadamente } \\
\text { ( ) Bastante }\end{array}$ & $\begin{array}{l}\text { ( ) Nada } \\
\text { ( ) Um pouco } \\
\text { ( ) Moderadamente } \\
\text { ( ) Bastante }\end{array}$ \\
\hline
\end{tabular}




$\begin{array}{llll}\text { TOTAL } & \mathbf{X} 100 & \mathbf{X} 100 & \mathbf{1 0 0}\end{array}$

PFIQ - 7 SCORE:

\section{Score do PFIQ-7:}

Todos os itens utilizam a seguinte escala de resposta:

0 - Nada, 1 - Um pouco, 2 - Moderadamente, 3 - Bastante

\section{Escalas:}

Urinary Impact Questionnaire (UIQ -7): 7 itens relacionados à coluna intitulada "Bexiga e urina".

Colorectal-Anal Impact Questionnaire (CRAIQ - 7): 7 itens relacionados à coluna intitulada "Intestino e reto".

Pelvic Organ Prolapse Impact Questionnaire (POPIQ - 7): itens relacionados à coluna "Pélvis e vagina".

Escala de Scores: Obtém-se a média de todos os itens respondidos na escala correspondente (valores possíveis: 0 a 3) e então multiplica-se por (100/3) para obter para obter o score da escala (0 a 100).

Itens não marcados são tratados utilizando-se a média apenas dos itens respondidos.

PFIQ - 7 Resumo do Score: Soma-se os scores das três escalas para obter-se o resumo do score (0 a 300). 


\section{ANEXO G - PATIENT GLOBAL IMPRESSION OF IMPROVEMENT (PGI - I)}

Circule um item que melhor descreve como a condição de seu trato urinário está agora, comparado como estava antes de você ter sido operado:

1 - Muito, muito melhor

2 - Muito melhor

3 - Um pouco melhor

4 - Sem mudanças

5 - Um pouco pior

6 - Muito pior

- Muito, muito pior 